\title{
Perfil físico-químico e sensorial de requeijão cremoso obtido a partir de diferentes coagulantes
}

\author{
Physical, chemical and sensorial profile of creamy cream cheese obtained from different coagulants \\ Perfil físico-químico y sensorial del requeijão cremoso obtenido de diferentes coagulantes
}

Recebido: 28/01/2021 | Revisado: 07/02/2021 | Aceito: 10/02/2021 | Publicado: 17/02/2021

Katyuscya Rodrigues Lima

ORCID: https://orcid.org/0000-0003-4943-2712 Instituto Federal de Educação, Ciência e Tecnologia Goiano, Brasil

E-mail: ka-tyuscya@hotmail.com

Jéssica Silva Medeiros

ORCID: https://orcid.org/0000-0002-9404-9045 Instituto Federal de Educação, Ciência e Tecnologia Goiano, Brasil

E-mail: jessicasilva.medeiros.sm@gmail.com

Paulo Victor Toledo Leão

ORCID: https://orcid.org/0000-0003-2213-1995 Instituto Federal de Educação, Ciência e Tecnologia Goiano, Brasil E-mail: paulovtbpv@gmail.com

João Vitor Teixeira da Cunha

ORCID: https://orcid.org/0000-0001-9651-3019 Instituto Federal de Educação, Ciência e Tecnologia Goiano, Brasil E-mail: texera07.jvt@gmail.com

Wemerson de Freitas Borges

ORCID: https://orcid.org/0000-0003-1702-8395 Instituto Federal de Educação, Ciência e Tecnologia Goiano, Brasil

E-mail: wemersoneborges@gmail.com

Givanildo de Oliveira Santos

ORCID: https://orcid.org/0000-0001-5279-1535 Instituto Federal de Educação, Ciência e Tecnologia Goiano, Brasil

E-mail: givanildo-o@ hotmail.com

João Antônio Gonçalves e Silva

ORCID: https://orcid.org/0000-0001-5121-1930 Instituto Federal de Educação, Ciência e Tecnologia Goiano, Brasil E-mail: joão.antoniogs@hotmail.com

Adriano Carvalho Costa

ORCID: https://orcid.org/0000-0003-1279-9756 Instituto Federal de Educação, Ciência e Tecnologia Goiano, Brasil E-mail: adriano.costa@ifgoiano.edu.br

Marco Antônio Pereira da Silva ORCID: https://orcid.org/0000-0002-3875-1104 Instituto Federal de Educação, Ciência e Tecnologia Goiano, Brasil

E-mail: marco.antonio@ifgoiano.edu.br

Edmar Soares Nicolau

ORCID: https://orcid.org/0000-0002-2512-3918 Universidade Federal de Goiás, Brasil E-mail: rena@cpa.evz.ufg.br

\begin{abstract}
Resumo
A inclusão da análise sensorial auxilia na percepção para aceitação no consumo dos alimentos, alguns fatores são identificados com variados métodos, como no presente estudo objetivou-se a avaliação das propriedades sensoriais e reológicas dos requeijões cremosos obtidos a partir de massas coaguladas por ácido acético, cítrico e lático. Para análise sensorial adotou-se duas etapas, a primeira por levantamento de 32 termos descritivos dos atributos: aparência, aroma, textura e sabor, aplicando o método Check-All-That-Apply (CATA), na segunda etapa realizada os testes de aceitação para os atributos, determinada pela escala hedônica estruturada de sete pontos e intenção de compra escala de cinco pontos. As metodologias aplicadas possibilitaram a identificação dos atributos mais relevantes das propriedades sensoriais dos requeijões cremosos. Para os dados estatístico das análises sensoriais utilizou-se teste Q de Cochran determinado pelo p-Valor a 5\% de significância e análise de correspondência, realizado pelo programa computacional R (R Core Team versão 3.6.3). Foram identificados valores dos requeijões cremosos que forneceram os resultados de 21 atributos.
\end{abstract}

Palavras-chave: Perfil sensorial; Queijo fundido; Acidulantes. 


\begin{abstract}
The inclusion of sensory analysis helps in the perception of acceptance of food consumption, some factors are identified with various methods, as in the present study, the objective was to evaluate the sensory and rheological properties of creamy curd obtained from pasta coagulated by acetic acid, citric and lactic. For sensory analysis, two steps were adopted, the first by surveying 32 descriptive terms of the attributes: appearance, aroma, texture and flavor, applying the Check-All-That-Apply method (CATA), in the second stage the acceptance tests were carried out for the attributes, determined by the structured hedonic scale of seven points and intention to purchase scale of five points. The applied methodologies made it possible to identify the most relevant attributes of the sensory properties of creamy curd. For the statistical data of the sensorial analyzes Cochran's Q test was used, determined by the p-Value at $5 \%$ of significance and correspondence analysis, performed by the computer program $\mathrm{R}$ (R Core Team version 3.6.3). Values of creamy curd were identified, which provided the results of 21 attributes.
\end{abstract}

Keywords: Sensory profile; Melted cheese; Organicacids.

\title{
Resumen
}

La inclusión del análisis sensorial ayuda en la percepción de aceptación del consumo de alimentos, se identifican algunos factores con diversos métodos, ya que en el presente estudio, el objetivo fue evaluar las propiedades sensoriales y reológicas de la cuajada cremosa obtenida de pasta coagulada por ácido acético, cítrico y láctico. Para el análisis sensorial se adoptaron dos pasos, el primero por relevar 32 términos descriptivos de los atributos: apariencia, aroma, textura y sabor, aplicando el método Check-All-That-Apply (CATA), en la segunda etapa se realizaron las pruebas de aceptación para los atributos, determinados por la escala hedónica estructurada de siete puntos y la escala de intención de compra de cinco puntos. Las metodologías aplicadas permitieron identificar los atributos más relevantes de las propiedades sensoriales de la cuajada cremosa. Para los datos estadísticos de los análisis sensoriales se utilizó la prueba Q de Cochran, determinada por el p-Value al 5\% de significancia y análisis de correspondencia, realizado por el programa informático $\mathrm{R}$ (R Core Team versión 3.6.3). Se identificaron valores de cuajada cremosa, que proporcionaron los resultados de 21 atributos.

Palabras clave: Perfil sensorial; Queso fundido; Acidulantes.

\section{Introdução}

Os dados da produção de leite no Brasil elaborados pelo Centro de Estudos Avançados em Economia Aplicada, registraram média de R\$ 1,5278 por litro no mês de junho de 2019, com uma porcentagem maior de $0,68 \%$ no mês de maio quando comparado ao ano de 2019 (Cepea, 2019).

A demanda por derivados lácteos tem crescido e, além disso, as mudanças nos hábitos de consumo, aumento do poder aquisitivo e condições de bem-estar das pessoas têm influenciado positivamente o consumo em países emergentes (Vilela et al., 2017).

Com a elevada demanda de produtos lácteos, cresceu também a exigência por produtos de qualidade, neste contexto, a produção de lácteos tomou proporções industriais em larga escala. Para acompanhar o elevado crescimento do consumo alimentício no Brasil e no mundo, são necessários sistemas produtivos eficazes, sustentáveis e de qualidade na elaboração da cadeia produtiva adequando às novas tecnologias do mercado globalizado e exigente, seguindo padrões para garantir aos consumidores finais, produtos de qualidade físico-químicas e sensoriais desejáveis (Saath \& Fachinello, 2018).

Ao longo dos anos vem se observando no Brasil o aumento na produção e comercialização de lácteos, o aumento acabou gerando fatores que transformaram o mercado lácteo nacional (Moraes \& Filho, 2017). A indústria de laticínios passou por importantes processos tecnológicos e desenvolvimento de novos produtos, para atender exigências dos consumidores, adotando programas no controle de qualidade, visando a diminuição de custos no processo, aumento da qualidade e diferenciação dos produtos lácteos ofertados ao consumidor (Maderi, 2014).

O requeijão cremoso é tipicamente brasileiro é um dos queijos mais apreciados, devido as suas propriedades sensoriais, é elaborado de massa fundida ou queijo processado, por interação entre calor e agitação, provendo a fusão a fim de obter um produto homogêneo e estável, utilizando emulsificantes, como os sais fundentes (Cruz et al., 2017).

$\mathrm{Na}$ fabricação de requeijões a utilização de ácidos permite mudanças físico-químicas no processamento, como controle de acidez e estabilidade (Talbot-Walsh et al., 2018). Contudo, as indústrias alimentícias buscam mecanismos para 
reduzir o custo das matérias-primas e fornecer produto de qualidade, os ácidos lático, cítrico e acético são bastante utilizados na elaboração de novos produtos, contribuindo nos processos tecnológicos de indústrias de laticínios.

Beux et al. (2017), relataram que aspectos tecnológicos na coagulação do leite, como a enzima coagulante, temperatura do leite, acidez titulável e proteínas, possuem características favoráveis no processo tecnológico, assim tendo impacto positivo no rendimento dos queijos.

Diferentes metodologias são aplicadas para dados reológicos, principalmente em alimentos que são elaborados por geometrias, equipamentos como cones, placas paralelas, ou cilíndricas, parâmetros avaliativos que indicam o tipo de rendimento, tensão, taxa de cisalhamento e viscosidade características de variados materiais, como espumas, graxas, géis, emulsões e pastas (Tucker, 2017).

A reologia representa a deformação de uma matéria sob a influência de tensões, de condições sólidas, líquidas e gás, indicando ações elásticas, fluidas, tração e cisalhamento (Schramm, 1994).

Desde modo as avaliações reológicas abordam temas de importância em múltiplos setores podendo ser aplicável nas indústrias alimentícias, farmacêuticas, cosmética e civis, agregando formulações durante as etapas: fabricação, prateleira e produto final, caracterizando economia e recurso ambos indústria e consumidor (Nae, 2016).

Todavia, as mudanças não são fáceis de serem implementadas e obter resultado positivo, seja do ponto de vista da melhoria do produto final, como no custo de produção. Mesmo assim, o emprego de diferentes compostos na elaboração dos produtos lácteos, enzimas e coagulantes podem ser exemplos de alternativas para a indústria alimentícia na busca de produto mais adequado e diferenciado (Castel et al., 2017).

Com a crescente demanda e avanços em processos tecnológicos alimentícios dos produtos lácteos, características sensoriais e segurança alimentar são essenciais aos consumidores, dessa forma, objetivou-se elaborar requeijão cremoso a partir de três coagulantes (ácidos lático, acético e cítrico), para avaliação dos parâmetros físico-químicos, propriedades reológicas e sensoriais avaliando a aceitabilidade por avaliação do método check-all-that-apply (cata), teste de escala hedônica e intenção de compra.

\section{Metodologia}

O presente trabalho se caracterizou como um estudo qualitativo e laboratorial, sendo que a metodologia qualitativa trata-se em grande parte da interpretação por parte do pesquisador com suas opiniões sobre o fenômeno em estudo, com isso, torna-se importante a prática reflexiva de ênfase social que se investiga e do processo de investigação (Pereira, et al. 2018).

\section{Leite in natura}

O leite refrigerado foi coletado no tanque de expansão do Laboratório de Bovinocultura Leiteira do IF Goiano Campus Rio Verde, GO, em galão de polipropileno com capacidade para 30 litros, previamente higienizado com água e detergente neutro, sanitizado com solução de hipoclorito de sódio (100,0ppm) por 30 minutos.

Após a coleta, o leite foi transportado ao Laboratório de Produtos de Origem Animal do IF Goiano - Campus Rio Verde, GO, para condução da pesquisa. Os requeijões cremosos foram processados em triplicata (três dias consecutivos) com uso dos ácidos: acético, cítrico e lático.

\section{Análises eletrônicas do leite}

Para análise eletrônica do leite foram coletadas amostras de leite in natura e desnatado em triplicata, acondicionadas em caixa isotérmica com gelo em gel reciclável e enviadas ao Laboratório de Qualidade do Leite do Centro de Pesquisa em Alimentos da Escola de Veterinária e Zootecnia da Universidade Federal de Goiás, Goiânia - GO. 
O leite foi acondicionado em frascos de $40,0 \mathrm{~mL}$ contendo conservante Bronopol ${ }^{\circledR}$, com homogeneização prévia, para análise da composição química e contagem de células somáticas (CCS).

Para análises de composição química do leite utilizou-se princípio analítico que se baseia na absorção diferencial de ondas infravermelhas pelos componentes do leite, utilizando equipamento Milkoscan 4000 (Foss Electric A/S. Hillerod, Denmark), para determinação de gordura, proteína, lactose, extrato seco total (EST), extrato seco desengordurado (ESD) do leite in natura e leite desnatado. As amostras foram previamente aquecidas em banho-maria à temperatura de $40,0^{\circ} \mathrm{C}$ por 15 minutos, para dissolução da gordura. Os resultados foram expressos em porcentagem (\%) (ISO/IDF, 2013).

Os teores de ureia e caseína foram determinados através do princípio analítico que se baseia na absorção diferencial de ondas infravermelhas transformada por Fourier - FTIR, utilizando o equipamento Lactoscope (Delta instruments). Os resultados de ureia foram expressos em mg por $\mathrm{dL}$, e caseína em porcentagem (\%).

A análise da CCS foi realizada de acordo com o princípio analítico que se baseia na citometria de fluxo realizada através do equipamento Fossomatic 5000 Basic (Foss Electric A/S. Hillerod, Denmark). Antes da análise, as amostras foram previamente aquecidas em banho-maria à temperatura de $40,0{ }^{\circ} \mathrm{C}$ por 15 minutos para dissolução da gordura. Os resultados foram expressos em Contagem de Células (CS) por mL (ISO/IDF, 2006).

\section{Desnate do leite}

Antes do desnate, o leite in natura foi submetido a pasteurização $\left(72,0^{\circ} \mathrm{C}\right.$ por 20 segundos). Os processamentos foram conduzidos de acordo com as Boas Práticas de Fabricação da RDC nº 275 (Brasil, 2002).

Para obtenção do leite desnatado e do creme de leite, o leite in natura foi submetido ao desnate (temperatura de 35,0 ${ }^{\circ} \mathrm{C}$ ) em desnatadeira (36 GR - Casa das Desnatadeiras ${ }^{\circledR}$ ) com capacidade de 100,0 L por hora. Os rendimentos de leite desnatado, creme de leite e massa ácida foram obtidos mediante a relação inicial de leite utilizada e o peso final resultante, com resultados expressos em $\mathrm{kg} 100 \mathrm{~kg}^{-1}$.

Após o desnate o creme de leite foi diluído na proporção 1:1 (creme de leite e leite desnatado). Em seguida leite e creme de leite foram estocados sob refrigeração a $5,0^{\circ} \mathrm{C}$ até o momento do processamento.

\section{Obtenção da massa ácida}

Após o desnate o leite foi pesado em três porções de $5,0 \mathrm{~kg}$ para obtenção da massa ácida, dando origem a três tratamentos (ácidos: acético, lático e cítrico).

Para obtenção da massa foi realizada a coagulação do leite desnatado, com aquecimento prévio à temperatura de 60,0 ${ }^{\circ} \mathrm{C}$, com adição dos coagulantes e a água em temperatura ambiente, homogeneizados totalizando em volumes de $99,0 \mathrm{~mL}$, 165,0 mL e 19,0 mL, respectivamente, de ácido acético (9,0 mL em 90,0 mL diluído de água), ácido lático (15,0 mL diluídos em 150,0 mL) e ácido cítrico (9,0 g diluídos em 10,0 mL de água).

\section{Processamento dos requeijões}

Os requeijões cremosos foram processados conforme metodologia descrita por Alves et al. (2015) com modificações. Para obtenção dos requeijões cremosos, a massa ácida foi obtida por meio da coagulação do leite desnatado com as misturas de água e dos ácidos: acético, lático e cítrico.

Após a coagulação do leite, as massas ácidas passaram pelo processo de viragem por 10 minutos, sendo intervalos de cinco minutos.

Os materiais adicionados foram: 250,0 g de massa ácida; 200,0 g de creme de leite diluído em 200,0 mL de leite desnatado; 6,0 g de sal (cloreto de sódio); 5,0 g de citrato de sódio e 100,0 mL de água. Posteriormente, foram liquidificadas 
por cinco minutos, sem aquecimento, em equipamento multiprocessador marca Philco ${ }^{\circledR}$ modelo all in one 2 citrus, de potência $800,0 \mathrm{~W}$ e $220 \mathrm{~V}$.

A cocção foi realizada à temperatura de $80,0^{\circ} \mathrm{C}$ em fogão industrial por sete minutos, em recipiente aberto. Após fusão, os requeijões cremosos foram envasados em frascos de vidro devidamente limpos, sanitizado, identificados e refrigerados na temperatura de $10,0^{\circ} \mathrm{C}$.

\section{Análises físico-químicas}

A umidade foi obtida pela perda do material submetido ao aquecimento em estufa (Thoth $250 \mathrm{~L}^{\circledR}$ ) a $105,0{ }^{\circ} \mathrm{C}$ por 24 horas, conforme o método oficial ${ }^{\circ} 925.10$ da AOAC (1995), a matéria seca foi calculada pela diferença do teor de umidade.

As cinzas foram determinadas por meio da carbonização total da matéria orgânica em forno mufla (Quimis ${ }^{\circledR}$ ) a 550,0 ${ }^{\circ} \mathrm{C}$, por cerca de 6 horas até obter cinzas claras, como descrito no método oficial n ${ }^{\circ} 945.46$ da AOAC, (2005).

A gordura foi avaliada através do Método de Gerber, segundo metodologia proposta pela Instrução Normativa $n^{\circ} 68$, de 12 de dezembro de 2006 (BRASIL, 2006).

A gordura no extrato seco (GES), foi calculada dividindo-se os teores de gordura do requeijão pelo teor de extrato seco total (EST), com resultado expresso em porcentagem (\%).

Para proteína bruta, determinou-se o nitrogênio total pelo método micro-Kjeldahl, multiplicando pelo fator de conversão 6,38 para lácteos. (IDF/ISSO 20-1/8968-1, 2014).

$\mathrm{O}$ pH da massa ácida e acidez titulável (ácido lático em \%) foram analisados segundo metodologia preconizada por Brasil, (2018).

As análises de cor foram realizadas em colorímetro (ColorFlex, EZ), os resultados foram expressos em L* (luminosidade), e coordenadas a* (positivo: vermelho, negativo : verde), $\mathrm{b}^{*}$ (positivo: amarelo, negativo :azul), $\mathrm{C}^{*}$ (Chroma: saturação) e hab (ângulo hue: tonalidade), conforme relatado por Paucar-Menacho et al., (2008), em seguida os dados foram submetidos a equação matemática no software Excel para determinação dos valores de Chroma e Hue, para o cálculo do Chroma foi utilizada a equação 1 e, para o Hue-Angle, utilizou-se a equação 2.

$$
\begin{array}{ll}
\mathrm{C}=\sqrt{ }(\mathrm{a} 2+\mathrm{b} 2) & \text { (Equação1) } \\
\mathrm{H}^{\mathrm{o}}=\operatorname{arctg} \mathrm{b}^{*} / \mathrm{a}^{*} & \text { (Equação2) }
\end{array}
$$

\section{Análises Reológicas dos requeijões cremosos}

A análise do perfil de viscosidade das amostras de requeijão cremoso foi realizada usando um analisador Reômetro Anton Paar - Physica MCR101 (Physica, MCR 101, Ostfildern, Germany), realizados pelo Laboratório Multiusuário de Análises (LabMulti) - Escola de Agronomia - UFG - Campus Samambaia, Goiânia - GO.

As análises reológicas foram realizadas nove amostras sendo submetidas a temperatura $8{ }^{\circ} \mathrm{C}$, em valores de taxa de cisalhamento entre 1 a $500 \mathrm{~s}^{-1}$ e varredura linear, por geometria de cone-placa (CP-50), o GAP de 0,1 mm (distância entre placas). Os dados experimentais foram expressos nos modelos reológicos (equação 3 e 4) da Lei da Potência ou Ostwald de Waale (Mathias et al., 2013). 


$$
\begin{aligned}
& n=k \dot{\gamma}^{\mathrm{n}-1}(\text { viscosidade) } \\
& \tau=k \dot{\gamma}^{\mathrm{n}} \text { (tensão) }
\end{aligned}
$$

\section{Análise sensorial}

Para a análise descritiva quantitativa Check-All-That-Apply (CATA), checagem de tudo o que necessário, o teste foi conduzido após a aprovação do Comitê de Ética em Pesquisa (CEP) do Instituto Federal de Educação, Ciência e Tecnologia Goiano (Parecer CEP/IF Goiano n ${ }^{\circ}$ 058624/2019; CAAE: $\mathrm{n}^{\circ}$ 14155219.9.0000.0036. Os testes aplicados foram quantitativos (aceitabilidade e intenção de compra) para 100 julgadores voluntários não treinados, com idade entre 18 e 46 anos, (58 mulheres e 42 homens), no Instituto Federal Goiano - Campus Rio Verde, composto de docentes, discentes e servidores.

A análise sensorial dos requeijões cremosos foi avaliada de três formulações com coagulantes (acético, cítrico e lático) em duas etapas. Inicialmente foram levantados atributos para análise descritiva, aplicando o método (CATA Check-AllThat-Apply), através de literaturas de estudos com requeijões cremosos, queijos processados, queijos análogos e derivados lácteos, dos seguintes autores (Oliveira et al., 2017) assim realizado o levantamento dos termos descritivos contendo 32 atributos: aparência, aroma, textura e sabor, representados na Tabela 4.

As amostras foram apresentadas aos julgadores de ordem aleatória, junta a ficha de CATA, servidas nas mesmas bandejas de isopor uma única vez, composta de água (temperatura ambiente), em copos descartáveis de $200 \mathrm{~mL}$, uma unidade de bolacha cream cracker, três amostras de requeijões cremosos (acético, cítrico e lático) em copos descartáveis de $50 \mathrm{~mL}$ com espátula, devidamente codificadas por números aleatórios de 3 dígitos. Todos julgadores foram orientados a provar as amostras da esquerda para direita, a beber água entre uma amostra e outra, a espalhar o requeijão cremoso na bolacha para avaliação.

Para teste de impressão global e aceitação os julgadores foram orientados a continuar avaliando as amostras dos requeijões cremosos com a ficha de impressão global e teste de aceitação e ficha, utilizando escalada hedônica de 7 pontos (7 gostei muito, 1 -desgostei muito) o julgador atribuiu para cada amostra uma nota, tanto para impressão global e teste de aceitação.

No teste de intenção de compra, utilizou-se escala estruturada 5 pontos (5 -certamente compraria, 1 - certamente não compraria).

\section{Análises estatísticas}

Para os parâmetros físico-químicos e reológicos foram conduzidas em delineamento inteiramente ao acaso (DIC), com três repetições por tratamento e triplicata de análises. As médias foram comparadas pelo teste de Tukey a 5,0\% de probabilidade, utilizando o software $\operatorname{SISVAR}^{\circledR}$ (Ferreira, 2011). O rendimento de leite desnatado e creme de leite foram apresentados de forma descritiva (Figura 4).

Para dados análise sensorial, utilizou-se teste Q de Cochran determinado pelo p-Valor a 5\% de significância e análise de correspondência, realizado pelo programa computacional R (R Core Team versão 3.6.3), para verificar possíveis diferenças entre amostras, determinando atributos sensoriais pelo teste $\mathrm{Q}$ de Cochran entre amostras utilizando dados de frequência dos atributos da lista CATA (Antúnez et al., 2017).

\section{Resultados e Discussão}

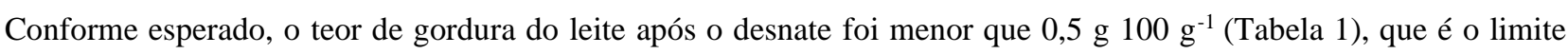
máximo de gordura do leite desnatado preconizado pela Instrução Normativa $\mathrm{n}^{\circ} 76$, de 26 de novembro de 2018, o leite 
integral deve apresentar no mínimo 3,0 g $100 \mathrm{~g}^{-1}$ de gordura (Brasil, 2018).

Tabela 1 - Valores médios e erro padrão da gordura, proteína, lactose, extrato seco total (EST), extrato seco desengordurado (ESD), contagem de células somáticas (CCS), ureia e caseína do leite in natura, e leite desnatado utilizado no processamento dos requeijões cremosos.

\begin{tabular}{lcc}
\hline \multirow{2}{*}{ Variáveis } & \multicolumn{2}{c}{ Leite } \\
\cline { 2 - 3 } & in natura & Desnatado \\
\hline Gordura $\left(\mathrm{g} 100 \mathrm{~g} \mathrm{~g}^{-1}\right)$ & $3,58 \pm 0,01^{\mathrm{a}}$ & $0,40 \pm 0,02^{\mathrm{b}}$ \\
Proteína $\left({\left.\mathrm{g} 100 \mathrm{~g}^{-1}\right)}^{\mathrm{a}}\right.$ & $3,28 \pm 0,01^{\mathrm{b}}$ & $3,39 \pm 0,00^{\mathrm{a}}$ \\
Lactose $\left(\mathrm{g} 100 \mathrm{~g}^{-1}\right)$ & $4,27 \pm 0,00^{\mathrm{b}}$ & $4,50 \pm 0,01^{\mathrm{a}}$ \\
EST $\left(\mathrm{g} 100 \mathrm{~g}^{-1}\right)$ & $12,15 \pm 0,01^{\mathrm{a}}$ & $9,22 \pm 0,02^{\mathrm{b}}$ \\
ESD $\left(\mathrm{g} 100 \mathrm{~g}^{-1}\right)$ & $8,57 \pm 0,00^{\mathrm{b}}$ & $8,82 \pm 0,01^{\mathrm{a}}$ \\
CCS $(\mathrm{CS}$ por $\mathrm{mL})$ & $558444,44 \pm 1465,44^{\mathrm{a}}$ & $227666,67 \pm 8000^{\mathrm{b}}$ \\
Ureia $(\mathrm{mg} \mathrm{por} \mathrm{dL})$ & $16,36 \pm 0,28^{\mathrm{a}}$ & $15,24 \pm 0,25^{\mathrm{b}}$ \\
Caseína $\left(\mathrm{g} 100 \mathrm{~g}^{-1}\right)$ & $2,60 \pm 0,01^{\mathrm{b}}$ & $2,67 \pm 0,01^{\mathrm{a}}$ \\
\hline
\end{tabular}

Letras distintas na linha diferem entre si ao nível de 5,0\% de acordo com teste de Tukey. Fonte: Autores (2021).

Segundo a legislação brasileira os valores mínimos de proteína devem ser de $2,9 \mathrm{~g} 100 \mathrm{~g}^{-1}$ e lactose 4,3 g $100 \mathrm{~g} \mathrm{~g}^{-1}$. Nas

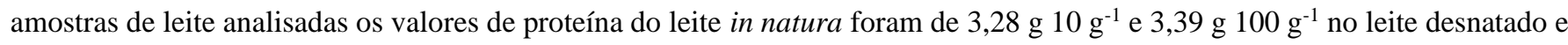
lactose de 4,27 g $100 \mathrm{~g}^{-1}$ no leite integral e leite desnatado 4,50 $100 \mathrm{~g} \mathrm{~g}^{-1}$. Portanto, o resultado de lactose do leite in natura foi ligeiramente inferior ao estabelecido pela legislação, porém, não inviabilizou o processamento dos requeijões, visto que o teor

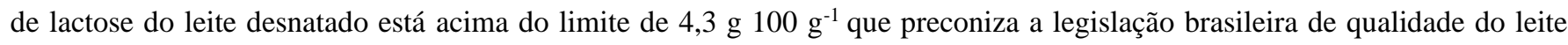
(Brasil, 2018).

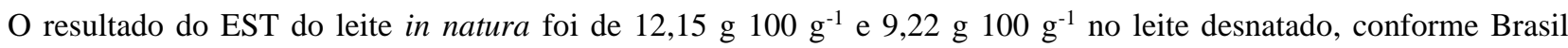
(2018), valores acima de 11,4 g $100 \mathrm{~g}^{-1}$ são adequados para recebimento e processamento do leite. Porém, com o desnate e consequente remoção da gordura o EST será inferior, o que já era esperado.

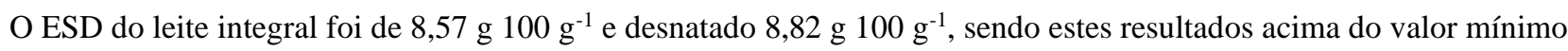
recomendado por Brasil (2018), que é 8,4 $\mathrm{g} 100 \mathrm{~g}^{-1}$.

Conforme pode ser visto na Tabela 1, a CCS ficou acima do valor de 500 mil CS por mL permitido para recebimento do leite in natura, porém, o desnate promove remoção das células somáticas do leite, que são carreadas para o creme de leite, resultando, portanto, em menor CCS no leite desnatado.

O nitrogênio ureico das amostras de leite in natura e desnatado foi respectivamente, 16,36 $\mathrm{mg}$ por dL e 15,24 mg por dL com diferença significativa $(\mathrm{P}<0,05)$. A ureia pode variar de 12,0 a $18,0 \mathrm{mg}$ por $\mathrm{dL}$, essas variações indicam dieta equilibrada em energia e proteína (Taffarel et al., 2010).

Os valores de caseína do leite in natura e desnatado apresentaram percentuais em relação a proteína abaixo de 80,0\%, conforme Alves et al., (2014) as caseínas representam 80,0 \% da proteína verdadeira e 20,0\% das proteínas do soro.

A Figura 1, demonstra o rendimento de leite desnatado e creme de leite obtidos no desnate do leite in natura. Do leite utilizado no desnate, $90,12 \%$ foi recuperado na forma de leite desnatado e $9,88 \%$ de creme de leite. 
Figura 1 - Rendimento de leite desnatado e creme de leite obtidos do desnate de leite in natura.

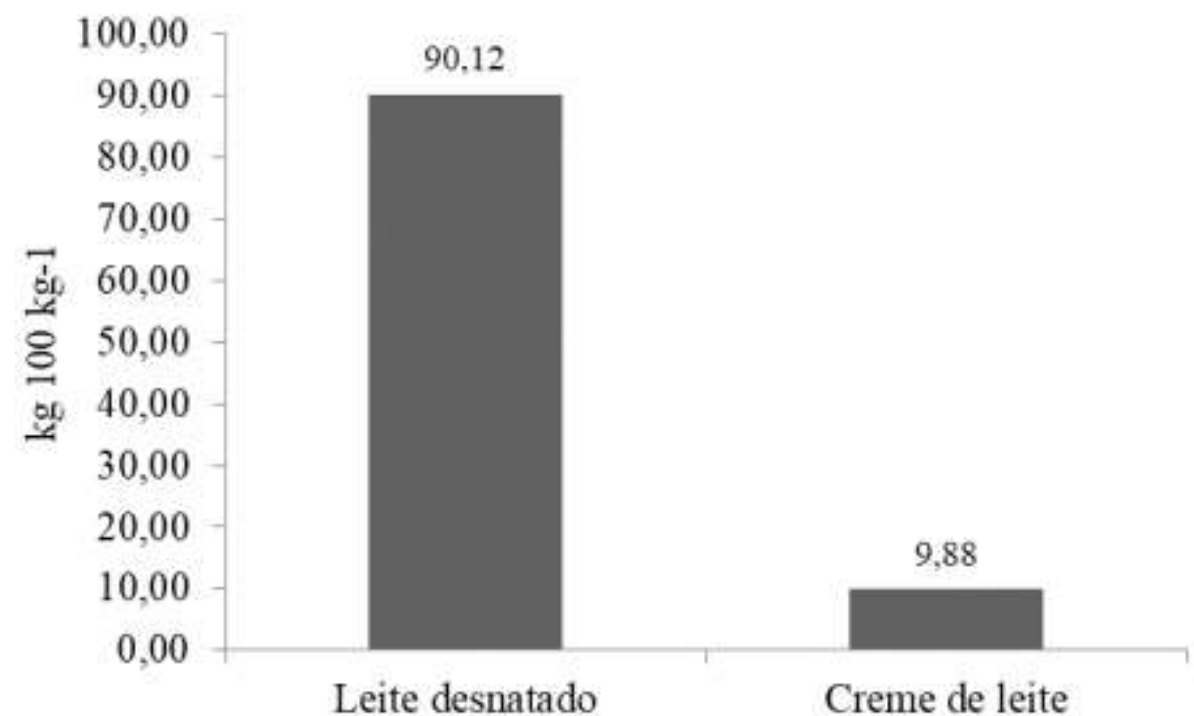

Fonte: Autores (2021).

Embora não existam dados na literatura que informem a porcentagem de creme de leite gerada durante o desnate do leite, supõe-se que possam variar os percentuais de gordura extraída conforme equipamentos, temperatura e métodos de desnate empregados pelas indústrias.

Os valores médios do pH da massa ácida e rendimento, encontram-se dispostos na Tabela 2.

Tabela 2 - Valores médios do pH e rendimento da massa ácida utilizada no processamento dos requeijões cremosos, obtido a partir de diferentes coagulantes.

\begin{tabular}{lccc}
\hline \multicolumn{1}{c}{ Variáveis } & \multicolumn{3}{c}{ Coagulantes } \\
\cline { 2 - 4 } & Acético & Cítrico & Lático \\
\hline $\mathrm{pH}$ da massa & $5,49 \pm 0,01^{\mathrm{a}}$ & $5,34 \pm 0,08^{\mathrm{a}}$ & $5,42 \pm 0,05^{\mathrm{a}}$ \\
Rendimento de massa $\left(\mathrm{kg} 100 \mathrm{~kg}^{-1}\right)$ & $10,70 \pm 0,23 \mathrm{~b}$ & $12,70 \pm 0,30^{\mathrm{a}}$ & $10,67 \pm 0,32 \mathrm{~b}$ \\
\hline
\end{tabular}

Letras distintas na linha diferem entre si ao nível de 5,0\% de acordo com teste de Tukey. Fonte: Autores (2021).

Para Dagostin (2011) a acidificação é resultante da produção natural do ácido lático por meio da fermentação de bactérias láticas. A utilização de ácidos orgânicos promove efeitos no processo de coagulação, e agem como reguladores de pH. Os valores de pH da massa ácida não diferiram entre si (P>0,05), foram respectivamente, 5,49; 5,34 e 5,42, para os ácidos acético, cítrico e lático. Em estudo de Zacarchenco et al. (2017) a massa apresentou pH entre 5,4 a 5,8.

O melhor rendimento entre os coagulantes utilizados na produção de massa ácida foi ácido cítrico, com valor de 12,70 $\mathrm{kg} 100 \mathrm{~kg}^{-1}$, já os coagulantes acético e lático não diferiram entre si $(\mathrm{P}>0,05)$ e apresentaram menor rendimento, porém, para uso do ácido cítrico como coagulante do leite em formulações de requeijão cremoso, recomenda-se atentar para a maior umidade da massa, que resultará em requeijões menos viscosos.

Os teores de matéria seca e umidade $(\mathrm{P}>0,05)$ dos requeijões não diferiram entre os coagulantes utilizados no processamento (Tabela 3), embora visualmente, a massa ácida tenha se apresentado menos viscosa, com consistência mais fluida. Os resultados de cinzas corroboram com esta afirmação, pois foi menor em comparação com as massas de acético e lático. 
Tabela 3 - Valores médios e erro padrão da matéria seca, umidade, cinzas, gordura, gordura no extrato seco (GES), proteína, acidez, $\mathrm{pH}$ e cor $\left(\mathrm{L}^{*}, \mathrm{a}^{*}, \mathrm{~b}^{*}\right.$, Chroma e Hue) dos requeijões cremosos obtidos a partir de diferentes coagulantes.

\begin{tabular}{lccc}
\hline \multicolumn{1}{c}{ Variáveis } & \multicolumn{3}{c}{ Coagulantes } \\
\cline { 2 - 4 } & Acético & Cítrico & Lático \\
\hline Matéria seca $\left({\left.\mathrm{g} 100 \mathrm{~g}^{-1}\right)}\right.$ & $33,79 \pm 0,25^{\mathrm{a}}$ & $33,34 \pm 0,07^{\mathrm{a}}$ & $34,03 \pm 0,37^{\mathrm{a}}$ \\
Umidade $\left(\mathrm{g} 100 \mathrm{~g}^{-1}\right)$ & $66,21 \pm 0,25^{\mathrm{a}}$ & $66,65 \pm 0,07^{\mathrm{a}}$ & $65,96 \pm 0,37^{\mathrm{a}}$ \\
Cinzas $\left(\mathrm{g} 100 \mathrm{~g}^{-1}\right)$ & $2,18 \pm 0,07^{\mathrm{a}}$ & $1,85 \pm 0,08^{\mathrm{b}}$ & $2,19 \pm 0,04^{\mathrm{a}}$ \\
Gordura $\left(\mathrm{g} 100 \mathrm{~g}^{-1}\right)$ & $11,00 \pm 0,00^{\mathrm{b}}$ & $12,00 \pm 0,00^{\mathrm{a}}$ & $11,00 \pm 0,00^{\mathrm{b}}$ \\
GES $\left(\mathrm{g} 100 \mathrm{~g}^{-1}\right.$ & $32,57 \pm 0,24^{\mathrm{b}}$ & $35,99 \pm 0,08^{\mathrm{a}}$ & $32,35 \pm 0,35^{\mathrm{b}}$ \\
Proteína $\left(\mathrm{g} 100 \mathrm{~g}^{-1}\right)$ & $10,78 \pm 0,28^{\mathrm{a}}$ & $9,20 \pm 0,23^{\mathrm{b}}$ & $10,85 \pm 0,34^{\mathrm{a}}$ \\
Acidez $\left(\mathrm{g} 100 \mathrm{~g}^{-1}\right)$ & $5,65 \pm 0,19^{\mathrm{b}}$ & $5,16 \pm 0,08^{\mathrm{c}}$ & $6,49 \pm 0,09^{\mathrm{a}}$ \\
pH & $6,18 \pm 0,01^{\mathrm{a}}$ & $6,15 \pm 0,03^{\mathrm{a}}$ & $6,12 \pm 0,01^{\mathrm{a}}$ \\
$\mathrm{L}^{*}$ & $81,50 \pm 0,16^{\mathrm{a}}$ & $81,45 \pm 0,16^{\mathrm{a}}$ & $78,39 \pm 0,33^{\mathrm{b}}$ \\
$\mathrm{a}^{*}$ & $-0,45 \pm 0,03^{\mathrm{a}}$ & $-0,85 \pm 0,04^{\mathrm{b}}$ & $-1,02 \pm 0,03^{\mathrm{c}}$ \\
b $^{*}$ & $17,64 \pm 0,14^{\mathrm{a}}$ & $16,37 \pm 0,08^{\mathrm{b}}$ & $14,19 \pm 0,12^{\mathrm{c}}$ \\
Chroma & $17,65 \pm 0,14^{\mathrm{a}}$ & $16,39 \pm 0,08^{\mathrm{b}}$ & $14,23 \pm 0,12^{\mathrm{c}}$ \\
Hue & $-873,35 \pm 0,98^{\mathrm{c}}$ & $-858,68 \pm 1,43^{\mathrm{b}}$ & $-847,40 \pm 1,27^{\mathrm{a}}$ \\
\hline
\end{tabular}

Letras distintas na linha diferem entre si ao nível de 5,0\% de acordo com teste de Tukey. Fonte: Autores (2021).

Em estudos de Ferrão et al., (2018) na elaboração de requeijões cremosos de diferentes teores de gorduras, observouse valores de umidade entre $64,77 \%$ e $76,08 \%$ caracterizando teores de umidade elevados e amostras com valores da matéria seca de $31,05 \%$ até $35,23 \%$.

Os requeijões cremosos foram classificados como queijos de alta umidade (geralmente conhecidos como de massa branda ou mole) com umidade maior que 55,0 g $100 \mathrm{~g}^{-1}$, segundo recomendações de Brasil, (1996).

Os valores de gordura dos requeijões com coagulantes acético e lático não diferiram entre si, com médias de $11,0 \mathrm{~g}$ $100 \mathrm{~g}^{-1}$ e o ácido cítrico, $12,0 \mathrm{~g} 100 \mathrm{~g}^{-1}$.

A GES do requeijão com coagulante ácido cítrico foi de $35,99 \mathrm{~g} 100 \mathrm{~g}^{-1}$, portanto, resultado maior, para acético e

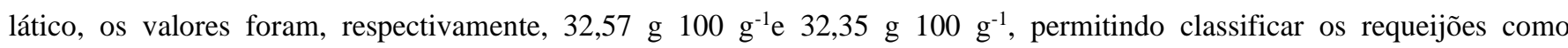
semigordos, quando contenham entre 25,0 g $100 \mathrm{~g}^{-1}$ e 44,9 g $100 \mathrm{~g}^{-1}$ de GES, conforme dispõe Brasil, (1996).

Os requeijões obtidos com ácido acético e lático apresentaram maior teor proteico em relação ao ácido cítrico, o que se pode inferir, que embora não tenham sido observadas diferenças no teor de matéria seca e umidade, para confirmação da menor viscosidade do requeijão obtido de ácido cítrico, apresentou-se mais gorduroso e menos proteico. De acordo com estudos de Silva et al., (2012) as propriedades de textura dos requeijões cremosos estão relacionadas a valores de gordura e de água, e pode ter interferido na consistência do requeijão cremoso.

As proteínas do leite possuem importância no processamento de derivados lácteos, valores de proteínas encontradas nos requeijões cremosos foram de 10,78\% para acético, 9,20\% cítrico e 10,85\% lático, apenas o coagulante cítrico teve diferença significativa de menor valor, devido possíveis alterações nas caseínas presentes, ocorrendo a desestabilidade na rede miscelar.

Hoffmann (2003) relatou que na elaboração do requeijão cremoso, as proteínas influenciam na retenção de água e propriedade emulsificante dispondo de maior teor de umidade e melhorando o rendimento do produto.

A amostra de massa ácida cítrica apresentou valores de 66,65\% de umidade, 12,0\% de gordura e 9,2\% de proteína, 
demonstrando variações em relação aos demais coagulantes. No estudo de Pinto (2015), valores com maior teor gordura, maior umidade e baixa proteína estão relacionados a sinérese que dificulta no processo de estabilização do produto.

Oliveira e Timm (2006) relataram a instabilidade de caseínas alterando a composição do leite, por causa da alimentação dos animais, à base de volumosos de alto teor de gordura. Fato que confirma o maior teor de gordura encontrado nas amostras de requeijões cremosos elaborados com o coagulante cítrico que apresentou 12,0\% de gordura.

Os resultados de acidez nas amostras dos requeijões cremosos foram de 5,65\%, 5,16\% e 6,49\%.

De acordo com Rodrigues et al. (2018), os parâmetros de pH não diferiam entre si, foram de 5,83 para ácido lático e 5,75 para ácido cítrico, observou-se que o coagulante cítrico diminuiu a viscosidade dos requeijões cremosos mesmo utilizando proporções diferentes (ácido lático 22,0\% e 20,0\% cítrico).

Parâmetros de pH dos requeijões cremosos não diferiram entre si, com valores de 6,18, 6,15 e 6,12, respectivamente, dos coagulantes acético, cítrico e lático.

Os resultados de acidez dos requeijões cremosos diferiram $(\mathrm{P}<0,05)$, lático foi maior, seguido por acético e cítrico, considerando a maior vida útil de produtos mais ácidos, recomenda-se o uso de ácido lático na obtenção de massa para processamento de requeijão cremoso.

Para Torres (2015) valores padrões da coordenada L* (luminosidade), variam de 0 a 100 , em que $0=$ preto e $100=$ branco. Neste estudo os valores de luminosidade foram de 81,50, 81,45 e 78,39, valores estes que se aproximam da cor branca.

No estudo de Sobral (2007) a coordenada a* indicou valores negativos, entre - 0,02 a 0,29, com proximidade da cor verde e valores de $b^{*}$ positivos indicando coordenadas tendendo a cor amarela com médias entre 8,41 e 13,68. Já nessa pesquisa as coordenadas b* indicaram médias de 17,64, 16,37 e 14,19 também sendo positivas, porém, apresentou diferenças significativas conforme Tabela 3.

Os valores de Chroma dos requeijões cremosos apresentaram médias de 17,65 (acético), 16,39 (cítrico) e 14,23 (lático) diferindo entre si. Fragoso et al., (2012) avaliaram sobremesas lácteas e relataram valores entre 13,87 a 14,83, sendo estas médias próximas do coagulante lático utilizado nessa pesquisa.

A tonalidade é definida pelo ângulo Hue, calculados a partir das coordenadas $\mathrm{a}^{*} \mathrm{e} \mathrm{b}^{*}$. Os valores médios desse estudo foram de -873,35 (acético), -858,68 (cítrico) e -847,40 (lático) com valores negativos presente na coordenada a*. No estudo de Presente (2015) todas as amostras de queijos indicaram valores negativos que tendem para a coordenada próximo da cor verde.

$\mathrm{Na}$ avaliação das propriedades sensoriais (Tabela 4), entre os 32 atributos mencionados pelos provadores dos requeijões cremosos entre os ácidos: acético, cítrico e lático(Tabela 4) 21 atributos apresentaram diferença significativa pelo teste de $\mathrm{Q}$ de Cochran $(\mathrm{P}<0,05)$ sendo: aparência (boa e ruim); cor (branca e amarela), brilho (presença de brilho) aroma (leite, queijo, natural de requeijão cremoso),textura; (homogênea, cremosa, mole, macia, fácil de espalhar e viscosa), sabor (ácido, salgado, leite, queijo, natural de requeijão cremoso, agradável e desagradável) e 11 atributos não apresentaram diferença significativa pelo teste de $\mathrm{Q}$ de Cochran $(\mathrm{P}>0,05)$ sendo: aparência(ausência de brilho), aroma (creme de leite; sem odor; agradável e desagradável), textura (presença de grânulos; dura e derrete na boca), sabor (creme de leite, residual e artificial de requeijão cremoso). 
Tabela 4 - Valores de frequência para cada atributo levantamento dos requeijões cremosos dos ácidos (acético, cítrico e lático) e resultados do teste Q de Cochran do questionário check-all-that (CATA).

\begin{tabular}{|c|c|c|c|c|c|}
\hline & \multirow{2}{*}{ Atributos } & \multicolumn{4}{|c|}{ Ácidos } \\
\hline & & Acético & Cítrico & Lático & p-valor \\
\hline \multirow[t]{2}{*}{ Aparência } & Boa & $89^{a}$ & $49^{b}$ & $86^{\mathrm{a}}$ & 0,001 \\
\hline & Ruim & $1^{\mathrm{b}}$ & $31^{\mathrm{a}}$ & $1^{\mathrm{b}}$ & 0,001 \\
\hline \multirow[t]{2}{*}{ Cor } & Branca & $59^{\mathrm{a}}$ & $38^{\mathrm{b}}$ & $58^{\mathrm{a}}$ & 0,001 \\
\hline & Amarela & $7^{\mathrm{b}}$ & $30^{\mathrm{a}}$ & $11^{\mathrm{b}}$ & 0,001 \\
\hline \multirow[t]{2}{*}{ Brilho } & Presença & $54^{\mathrm{a}}$ & $42^{b}$ & $60^{\mathrm{a}}$ & 0,001 \\
\hline & Ausência & 9 & 12 & 5 & 0,157 \\
\hline \multirow[t]{7}{*}{ Aroma } & Creme de leite & 20 & 19 & 18 & 0,924 \\
\hline & Leite & $24^{\mathrm{a}}$ & $34^{\mathrm{a}}$ & $13^{\mathrm{b}}$ & 0,001 \\
\hline & Queijo & $12^{\mathrm{a}}$ & $4^{b}$ & $5^{\mathrm{b}}$ & 0,034 \\
\hline & Sem odor & 34 & 32 & 40 & 0,314 \\
\hline & Agradável & 39 & 31 & 29 & 0,192 \\
\hline & Desagradável & 5 & 8 & 3 & 0,281 \\
\hline & Natural de requeijão cremoso & $33^{\mathrm{a}}$ & $19^{\mathrm{b}}$ & $33^{\mathrm{a}}$ & 0,012 \\
\hline \multirow[t]{9}{*}{ Textura } & Homogênea & $58^{\mathrm{a}}$ & $39^{\mathrm{b}}$ & $63^{\mathrm{a}}$ & 0,001 \\
\hline & Presença de grânulos & 5 & 5 & 2 & 0,406 \\
\hline & Cremosa & $78^{\mathrm{a}}$ & $12^{\mathrm{b}}$ & $63^{\mathrm{a}}$ & 0,001 \\
\hline & Mole & $4^{\mathrm{c}}$ & $83^{\mathrm{a}}$ & $28^{\mathrm{b}}$ & 0,001 \\
\hline & Macia & $27^{\mathrm{a}}$ & $7^{\mathrm{b}}$ & $9^{\mathrm{b}}$ & 0,001 \\
\hline & Dura & 1 & 0 & 1 & 0,606 \\
\hline & Fácil de espalhar & $44^{\mathrm{a}}$ & $30^{\mathrm{b}}$ & $49^{\mathrm{a}}$ & 0,001 \\
\hline & Viscosa & $21^{\mathrm{a}}$ & $7^{\mathrm{b}}$ & $9^{\mathrm{b}}$ & 0,001 \\
\hline & Derrete na boca & 38 & 27 & 38 & 0,076 \\
\hline \multirow[t]{10}{*}{ Sabor } & Ácido & $9^{\mathrm{a}}$ & $15^{\mathrm{b}}$ & $2^{\mathrm{b}}$ & 0,001 \\
\hline & Salgado & $28^{\mathrm{ab}}$ & $37^{\mathrm{a}}$ & $23^{\mathrm{b}}$ & 0,034 \\
\hline & Leite & $11^{\mathrm{b}}$ & $31^{\mathrm{a}}$ & $13^{\mathrm{b}}$ & 0,001 \\
\hline & Creme de leite & 19 & 15 & 26 & 0,109 \\
\hline & Queijo & $22^{\mathrm{a}}$ & $15^{\mathrm{b}}$ & $11^{\mathrm{b}}$ & 0,031 \\
\hline & Residual & 1 & 4 & 3 & 0,367 \\
\hline & Natural de requeijão cremoso & $48^{\mathrm{a}}$ & $24^{\mathrm{b}}$ & $53^{\mathrm{a}}$ & 0,001 \\
\hline & Artificial de requeijão cremoso & 14 & 12 & 7 & 0,223 \\
\hline & Agradável & $68^{\mathrm{a}}$ & $32^{\mathrm{b}}$ & $62^{\mathrm{a}}$ & 0,001 \\
\hline & Desagradável & $2^{\mathrm{b}}$ & $23^{\mathrm{a}}$ & $4^{\mathrm{b}}$ & 0,001 \\
\hline
\end{tabular}

p-valor: Teste $\mathrm{Q}$ de Cochran $(\mathrm{P}<0,05)$. Letras sobrescritas semelhantes em uma mesma linha indicam igualdade estatística pelo teste de Mc Nemar $(\mathrm{P}<0,05)$. Fonte: Autores (2021).

O atributo de maior percepção pelos julgadores foi de aparência boa e cor branca, em requeijões cremosos elaborados com ácidos, acético e lático e maior atributo ruim e cor amarela e de menor brilho para cítrico. Chenget al., (2019) relataram, 
que a cor branca em produtos lácteos pode estar relacionada aos valores de gordura e proteína, dessa forma os requeijões cremosos elaborados com ácido cítrico obtiveram de maior concentração de gordura e menor proteína em relação aos demais ácidos, fatores que comprovam maior percepção dos julgadores em requeijões do ácido cítrico quanto o atributo aparência de cor amarela.

No estudo de Torres et al. (2017) em avaliação de diferentes tipos requeijões cremosos, julgadores relataram que atributos aroma e sabor requeijão cremoso foram semelhantes.

Para o atributo textura homogênea, cremosa e fácil de espalhar verificou-se maior percepção em requeijões cremosos acético e lático, já no ácido cítrico maior percepção para uma textura mole. De acordo com Perveen et al. (2011), aspectos como sinérese podem interferir na instabilidade do produto, comprometendo uma textura menos firme, fatores relacionados ao teor de gordura encontrado nos requeijões cremosos de ácido cítrico.

No estudo de Rodrigues et al. (2018), identificaram maior valor da acidez adicionada ao produto com ácido cítrico ao avaliarem diferentes formulações testes, notou-se que a adição dos ácidos diminuiu a viscosidade do produto. Brighenti et al. (2018), relataram que produtos como cream cheese contendo alto teor de gordura afetaram a textura ficando mole, menos consistente e mais fácil de espalhar.

Fennema et al. (2010), descreveram que o teor de gordura é um dos fatores que podem influenciar na textura dos alimentos, variando estado físico e fonte alimentar, desta forma nesta pesquisa o requeijão cremoso de ácido cítrico apresentou sabor indesejável principalmente nos atributos como textura e sabor.

Resultados do levantamento dos termos descritivos contendo 32 atributos: aparência, aroma, textura e sabor, foram obtidos de literaturas que aplicaram testes sensoriais em queijos processados, queijos análogos e derivados lácteos. Frequência dos atributos foram realizadas por análises demonstradas apenas as características que apresentaram diferença pelo teste Q de Cochran. A Figura 2, representa os atributos levantados dos requeijões cremosos: gráfico sem sombra.

Figura 2 - Representação do levantamento dos 32 atributos do questionário check-all-that-apply (CATA) das amostras de requeijões cremosos.

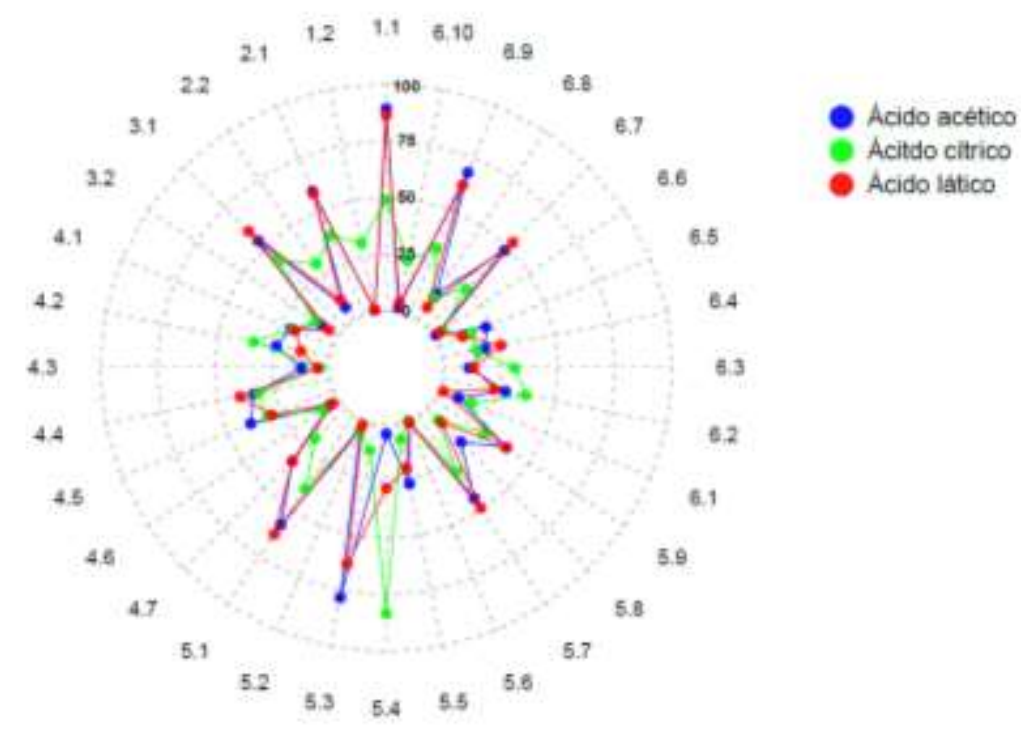

1.1 - Aparência boa, 1.2 - aparência ruim, 2.1 -cor branca, 2.2 - cor amarela, 3.1 -presença de brilho, 3.2 -ausência de brilho, 4.1 - aroma de creme de leite, 4.2 - aroma de leite, 4.3 - aroma de queijo, 4.4 - sem odor, 4.5 - aroma agradável, 4.6 - aroma desagradável, 4.7 - aroma natural de requeijão cremoso, 5.1 - textura homogênea , 5.2 - presença de grânulos, 5.3 - textura cremosa, 5.4 - textura mole, 5.5 - textura macia, 5.6 - textura dura, 5.7 textura fácil de espalhar, 5.8 - textura viscosa, 5.9 - derrete na boca, 5.9 - sabor ácido, 6.1 - sabor salgado, 6.2 - sabor de leite, 6.3 sabor de creme de leite, 6.4 - sabor de queijo, 6.5 - sabor residual, 6.6 - sabor natural de requeijão cremoso, 6.7 - sabor artificial de requeijão cremoso, 6.9 - sabor agradável, 6.10 sabor desagradável. Fonte: Autores (2021). 
Figura 3 - Representação da intenção de compra dos requeijões cremosos analisados por escala hedônica de 5 pontos.

\section{Certamente compraria}

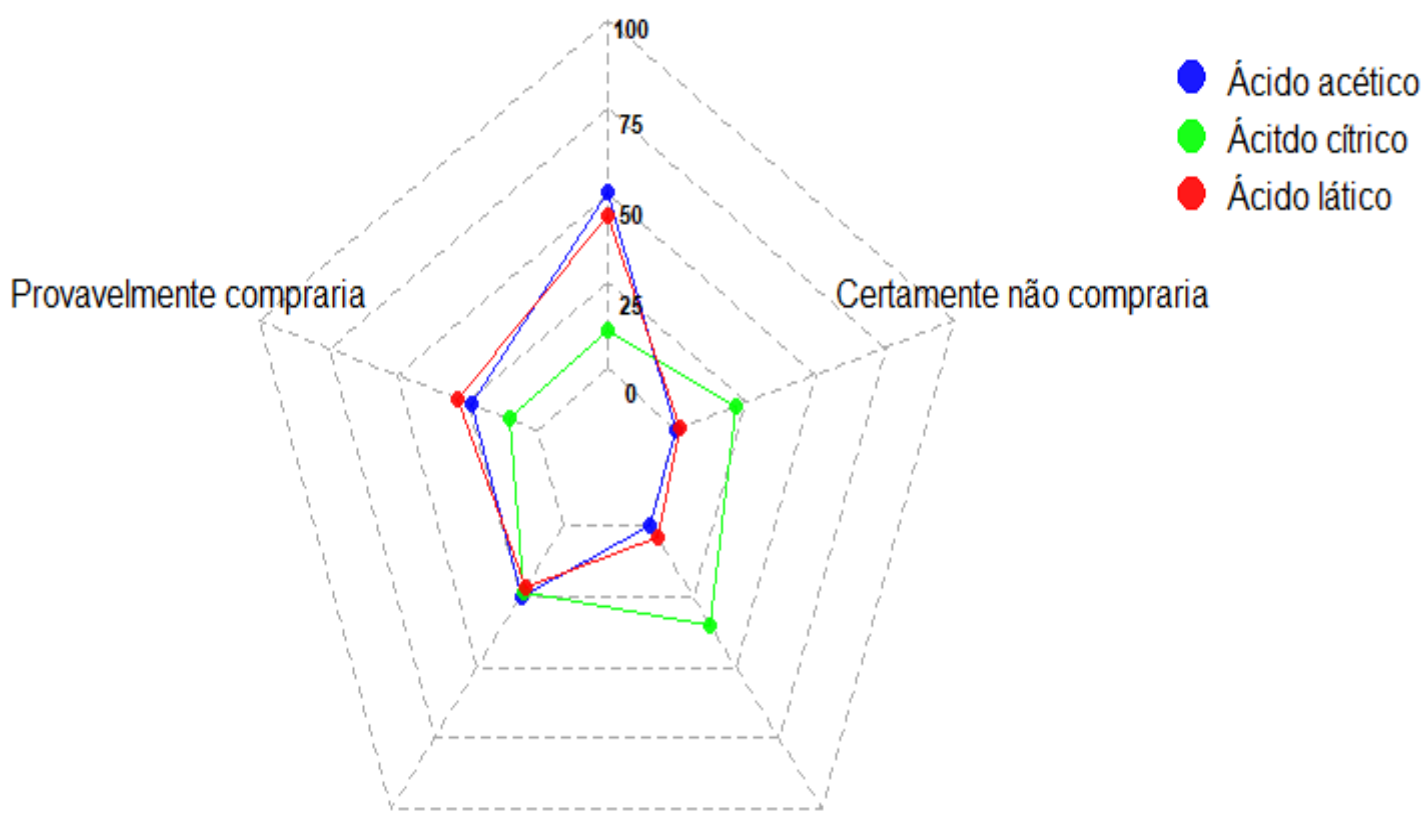

Talvez compraria

Provavelmente não compraria

Intenção de compra dos requeijões cremosos - Dados de frequência obtidos durante a análise para as categorias: Certamente compraria; provavelmente compraria; Talvez compraria; Provavelmente não compraria e Certamente não compraria. Fonte: Autores (2021).

Para Torres et al., (2017) a qualidade do requeijão cremoso consiste em atributos de sabor, aroma, espalhabilidade, homogeneidade, cremosidade, derretido na boca e brilho, sendo desejável em queijos processados. Na Figura 3, foi possível indicar a aceitação de intenção de compra das amostras de requeijões cremosos, onde os julgadores tiveram maior preferência pelas amostras de ácido acético e lático indicando que certamente compraria ou provavelmente compraria o produto, também obtiveram melhor aceitação por escala hedônica na Figura 4, quanto a impressão global de cada amostra. 
Figura 4 - Representação em medida da média das notas de impressão global dos atributos quanto à aroma, cor, sabor e textura dos requeijões cremosos analisados por escala hedônica de 7 pontos.

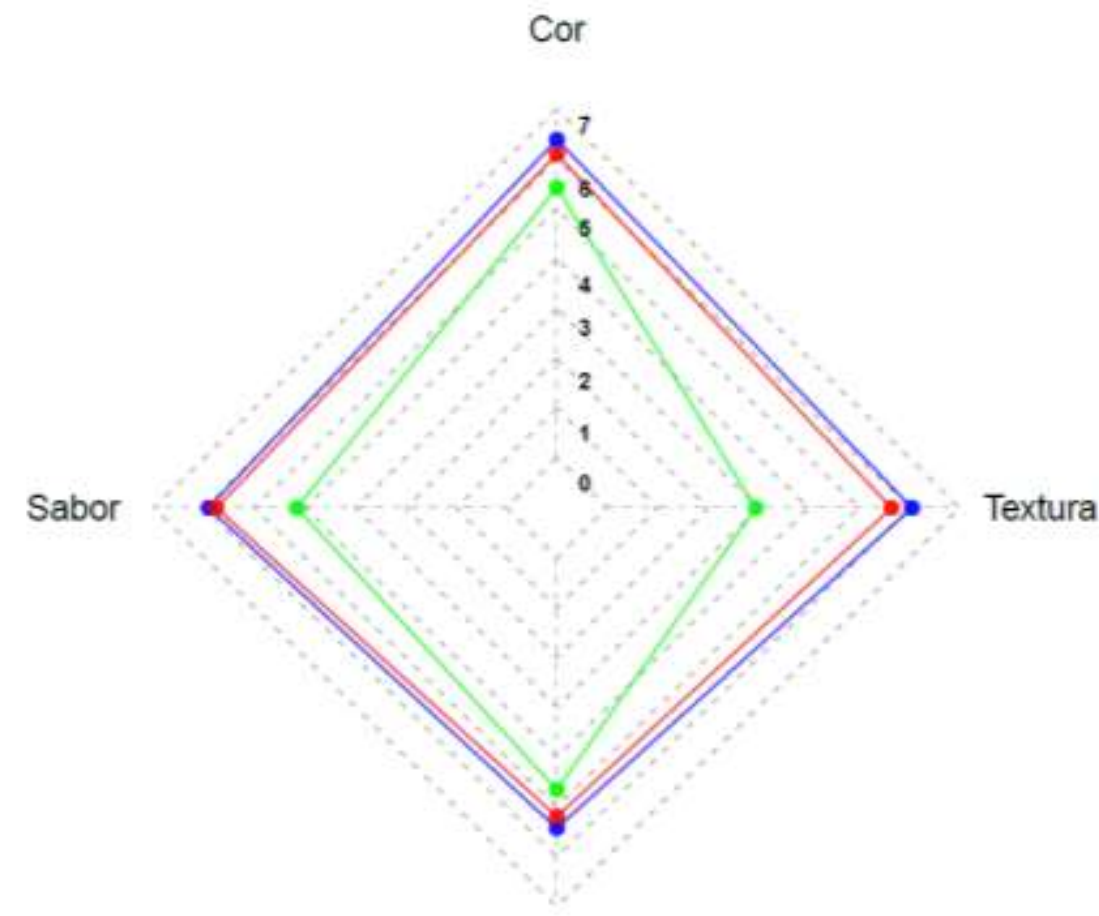

- Ácido acético

Ácitdo citrico

Ácido lático

\section{Aroma}

Média das notas dos atributos obtida para categoria (Cor, Sabor, Aroma e Textura), (7 Gostei muito; 6 Gostei moderadamente; 5 Gostei ligeiramente; 4 Nem gostei nem desgostei; 3 Desgostei ligeiramente; 2 Desgostei moderadamente; e 1 Desgostei muito). Fonte: Autores (2021)

A média para dados em impressão global dos requeijões cremosos elaborados com acético e lático indicaram semelhanças para os quatros atributos e já ácido cítrico de menores notas indicadas pelos julgadores, (Figura 2) que indica intenção compra pela escala de 5 pontos o mesmo foi apontado com notas de certamente não compraria e provavelmente não compraria. Informações que estão relacionadas a textura do produto, como apontada (Figura 3 e 4). 
Figura 5 - Representação em medida da moda das notas de impressão global dos atributos quanto aroma, cor, sabor e textura dos requeijões cremosos analisados por escala hedônica de 7 pontos.

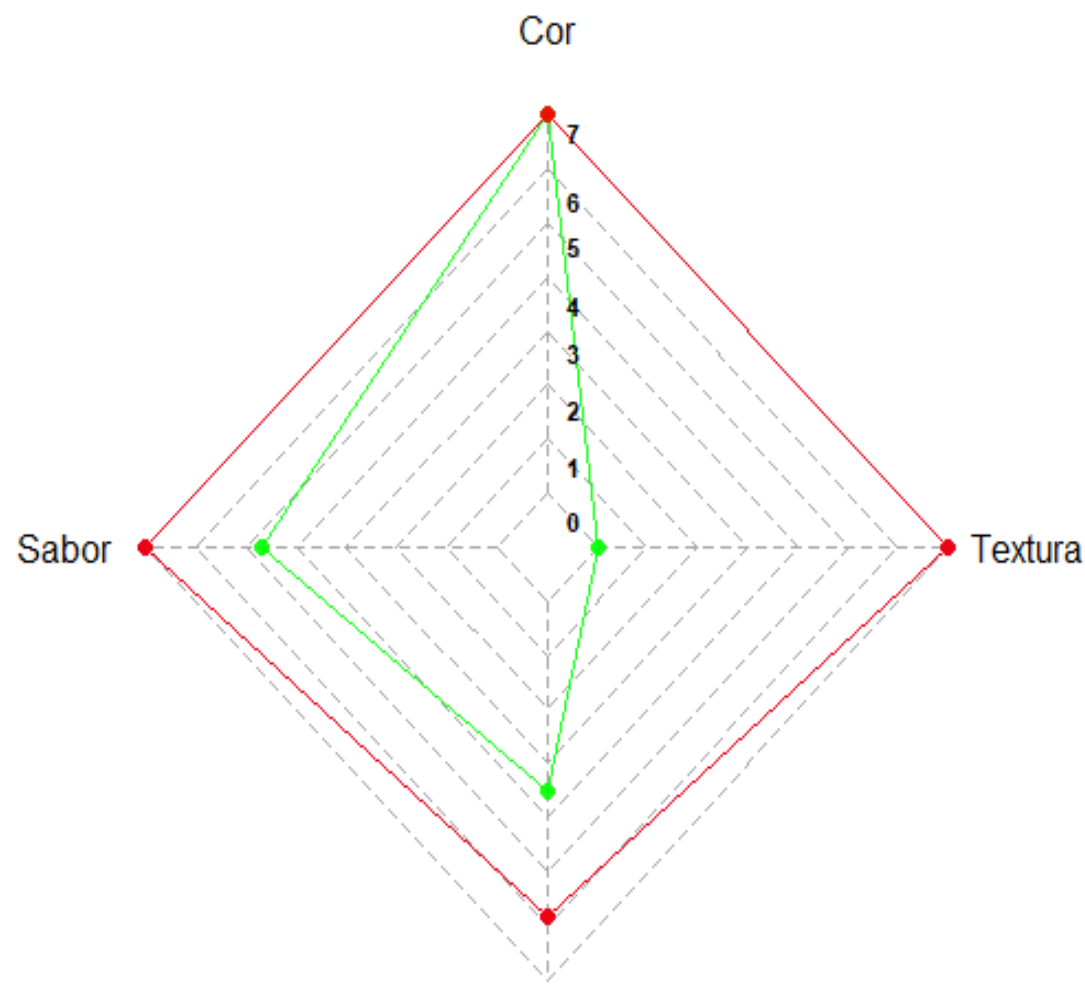

Ácido acético

Ácitdo cítrico

- Ácido lático

\section{Aroma}

Representação gráfica em moda das notas dos atributos obtida para categorias: (Cor, Textura, Aroma e Sabor), por escala hedônica (7 Gostei muito; 6 Gostei moderadamente; 5 Gostei ligeiramente; 4 Nem gostei nem desgostei; 3 Desgostei ligeiramente; 2 Desgostei moderadamente; e 1 Desgostei muito). Fonte: Autores (2021).

Nos quatros atributos cor, textura, aroma e sabor, nota-se que os requeijões cremosos, elaborados com ácido acético e lático obtiveram notas iguais indicados na linha vermelha, sendo que os atributos foram próximos das notas 7 gostei muito e 6 gostei moderadamente. O requeijão cremoso ácido cítrico apesar de demonstrar atributos inferiores quanto textura, sabor e aroma, ainda indicou semelhança no quesito cor, embora para a textura recebeu nota inferior, 1 desgostei muito. 
Figura 6 - Representação das cinco variáveis maior relevância da análise de correspondência da frequência do levantamento dos atributos do método check-all-that-apply (CATA) das amostras de requeijões cremosos.

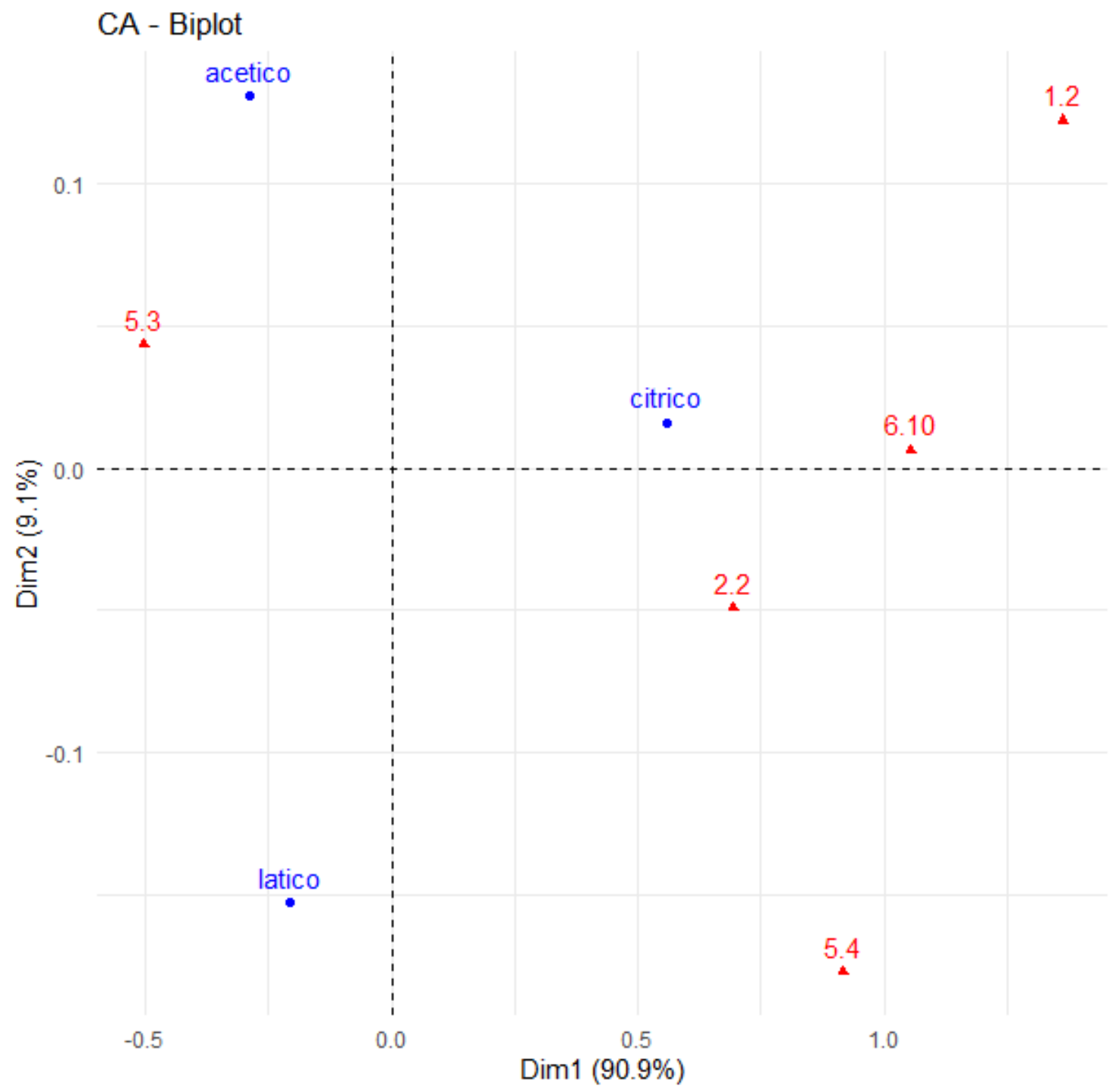

Atributos de maior relevância entre os requeijões cremosos dos ácidos: acético, cítrico e lático. Fonte: Autores (2021).

Conforme a Figura 5 indicou notas em escala hedônica que o requeijão cremoso ácido cítrico quanto a textura e aparência não foi aceitável sensorialmente, o que também demonstram neste gráfico de dimensões (Figura 6), de atributos de maior relevância dos requeijões cremosos, sendo os itens1.2. Aparência ruim; 2.2. cor amarela; 5.4. textura mole,5.3. textura cremosa e 10. Sabor desagradável. 
Figura 7 - Representação da análise de correspondência da frequência dos 32 atributos levantados do método check-all-thatapply (CATA) das amostras de requeijões cremosos.

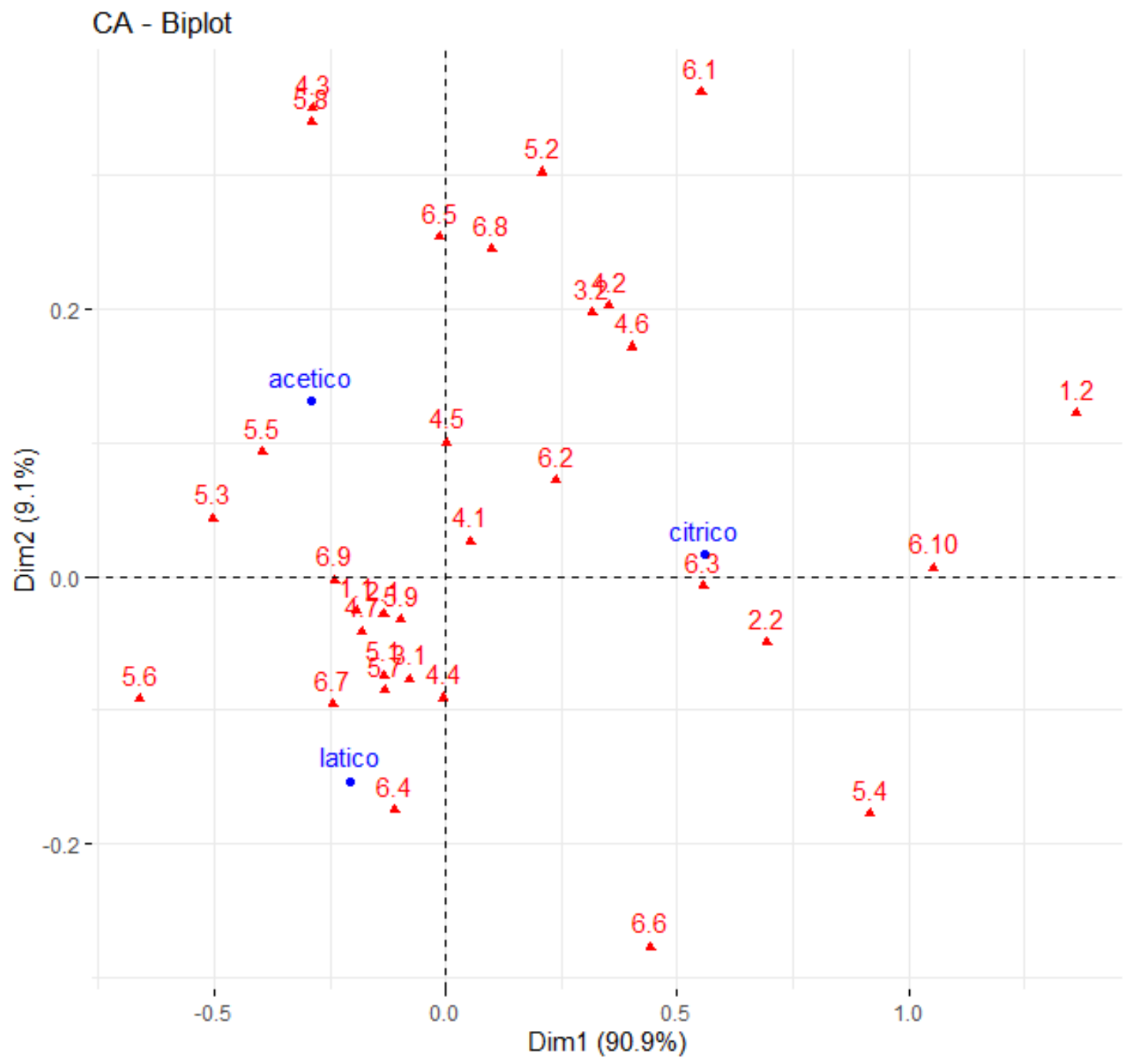

1. Aparência (1.1. Aparência boa; 1.2. Aparência ruim); 2. Cor (2.1. Branca; 2.2. Amarela); 3. Brilho (3.1. Presença de brilho; 3.2. Ausência de brilho); 4. Aroma (4.1. Creme de leite; 4.2. Leite; 4.3. Queijo; 4.4. Sem odor; 4.5. Agradável; 4.6. Desagradável; 4.7. Natural de requeijão cremoso 5. Textura; (5.1. Homogênea; 5.2. Presença de grânulos; 5.3. Cremosa; 5.4. Mole; 5.5. Macia; 5.6. Dura; 5.7. Fácil de espalhar; 5.8. Viscosa; 5.9. Derrete na boca); 6. Sabor (6.1. Ácido; 6.2. Salgado; 6.3. Leite; 6.4. Creme de leite; 6.5. Queijo; 6.6. Residual; 6.7. Natural de requeijão cremoso; 6.8. Artificial de requeijão cremoso; 6.9. Agradável; 6.10. Desagradável). Fonte: Autores (2021).

$\mathrm{Na}$ Figura 7, foram apresentadas as dimensões dos atributos sensoriais, da categoria aroma e sabor indicaram semelhanças entre os três ácidos, sendo de aroma: sem odor (4.4) e agradável (4.5) e sabor de queijo (6.5). Levando em consideração os requeijões cremosos, os ácidos acético e lático em relação a primeira dimensão apresentaram comportamento similares e ao contrário ácido cítrico. O requeijão cremoso elaborado com ácido cítrico apresentou 14 atributos na dimensão 1 . Aparência e cor: ruim, amarela e ausência de brilho. Aroma: creme de leite, leite, desagradável. Textura: presença de grânulos, mole. Sabor: ácido, salgado, leite, residual, artificial de requeijão cremoso, desagradável.

Na dimensão 2 foram apontados os requeijões cremosos de ácido acético e lático. O ácido acético de Aroma: queijo; Textura: cremosa, macia, viscosa; Sabor: agradável e no ácido lático de Aparência e cor: boa, branca, presença de brilho; Aroma: natural de requeijão cremoso; Textura: derrete na boca, homogênea, fácil de espalhar, dura; Sabor: natural de requeijão cremoso e creme de leite. 


\section{Análises reológicas}

As amostras de requeijões cremosos AA (ácido acético), AC (ácido cítrico) e AL (ácido lático) foram analisadas quanto ao comportamento de fluxo da viscosidade, o melhor modelo ajustado foi lei de potência, (Figuras 8, 9, 10, 11, 12 e 13) com parâmetros de viscosidade, tensão e taxa de cisalhamento. Resultados demostram que ácido acético atingiu melhor $\mathrm{n}$ (índice de comportamento), representados na Figura 12, valores das três amostras de ácido acético foram semelhantes entre si (Figura 14). A taxa de viscosidade atingiu 100k (Pa.s) e ácido lático bem próximo, valores que foram observados pelos julgadores no atributo textura e na aceitação do ácido cítrico uma rejeição de textura mole, que revela queda na taxa de cisalhamento (Figura 9).

Bayarri et al. (2012), investigaram propriedades mecânicas e viscoelasticidade, analisando alterações, de diferentes temperaturas em queijos cremosos, revelando amostras com características sólidas, firmes, mais aderentes e menos dispersáveis devido aos teores de gordura e proteína, parâmetros que contribuem na produção de formulações e qualidade nos produtos alimentícios.

Figura 8 - Curvas de tensão de cisalhamento $\left(\mathrm{s}^{-1}\right)$ e viscosidade (Pa.s) das amostras de requeijões cremosos. AAI (ácido acético amostra 1), AAII (ácido acético amostra 2), AAIII (ácido acético amostra 3).

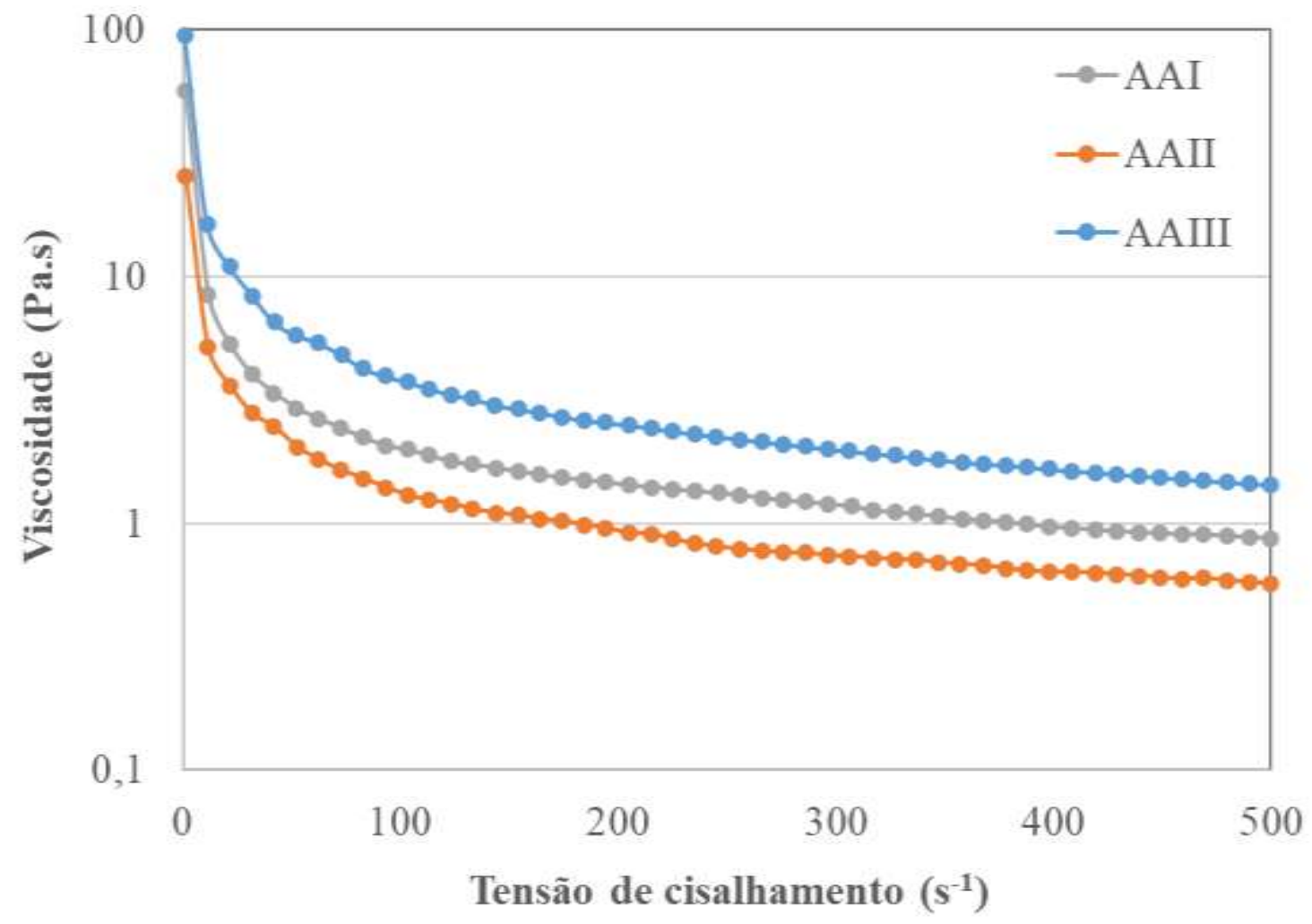

Fonte: Autores (2021). 
Figura 9 - Curvas de tensão de cisalhamento $\left(\mathrm{s}^{-1}\right)$ e viscosidade (Pa.s) das amostras de requeijões cremosos. ACI (ácido cítrico amostra 1), ACII (ácido cítrico amostra 2), ACIII (ácido cítrico amostra 3).

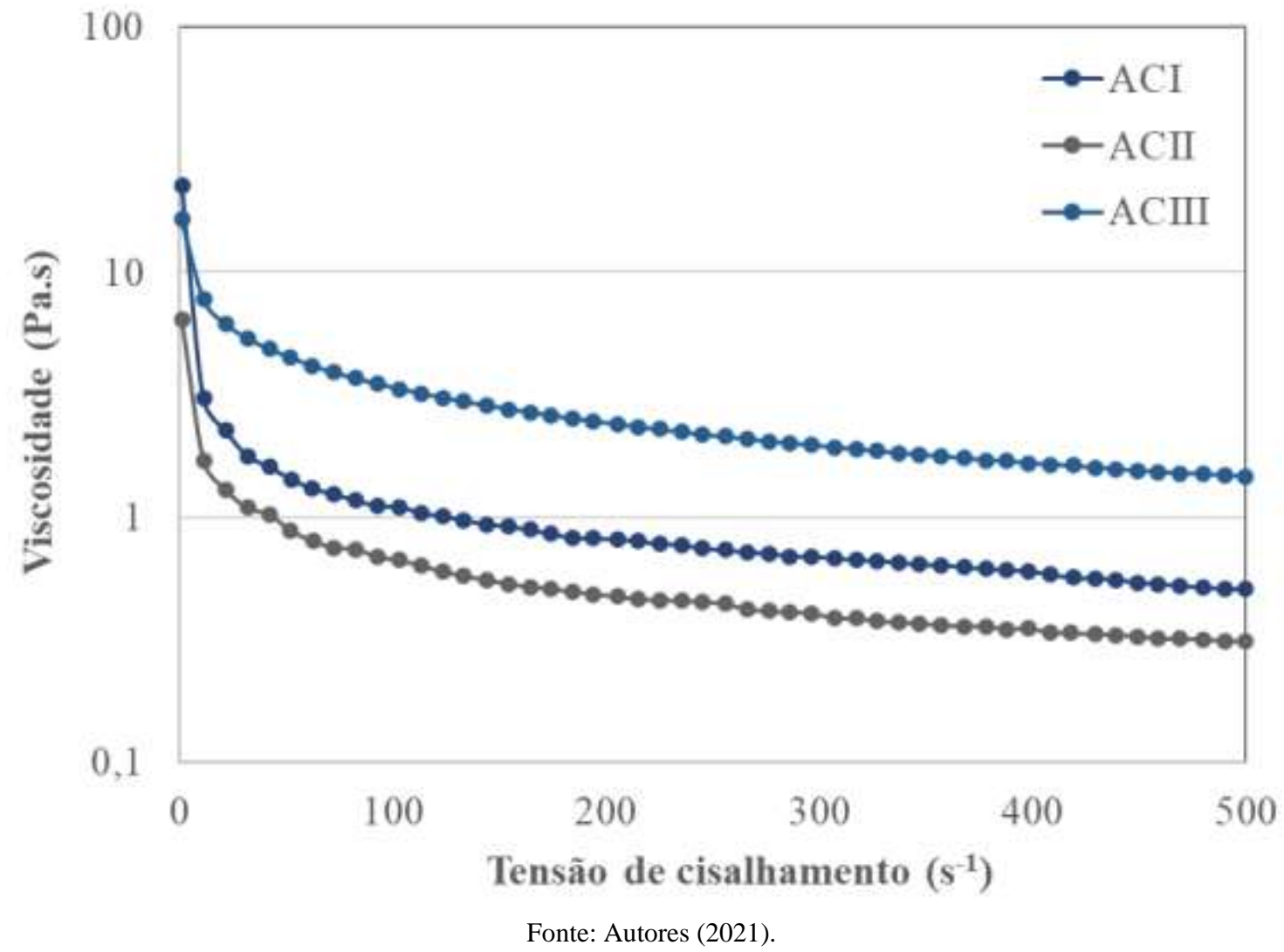

Figura 10 - Curvas de tensão de cisalhamento $\left(\mathrm{s}^{-1}\right)$ e viscosidade (Pa.s) das amostras de requeijões cremosos ALI (ácido lático amostra 1), ALII (ácido lático amostra 2), ALIII (ácido lático amostra 3).

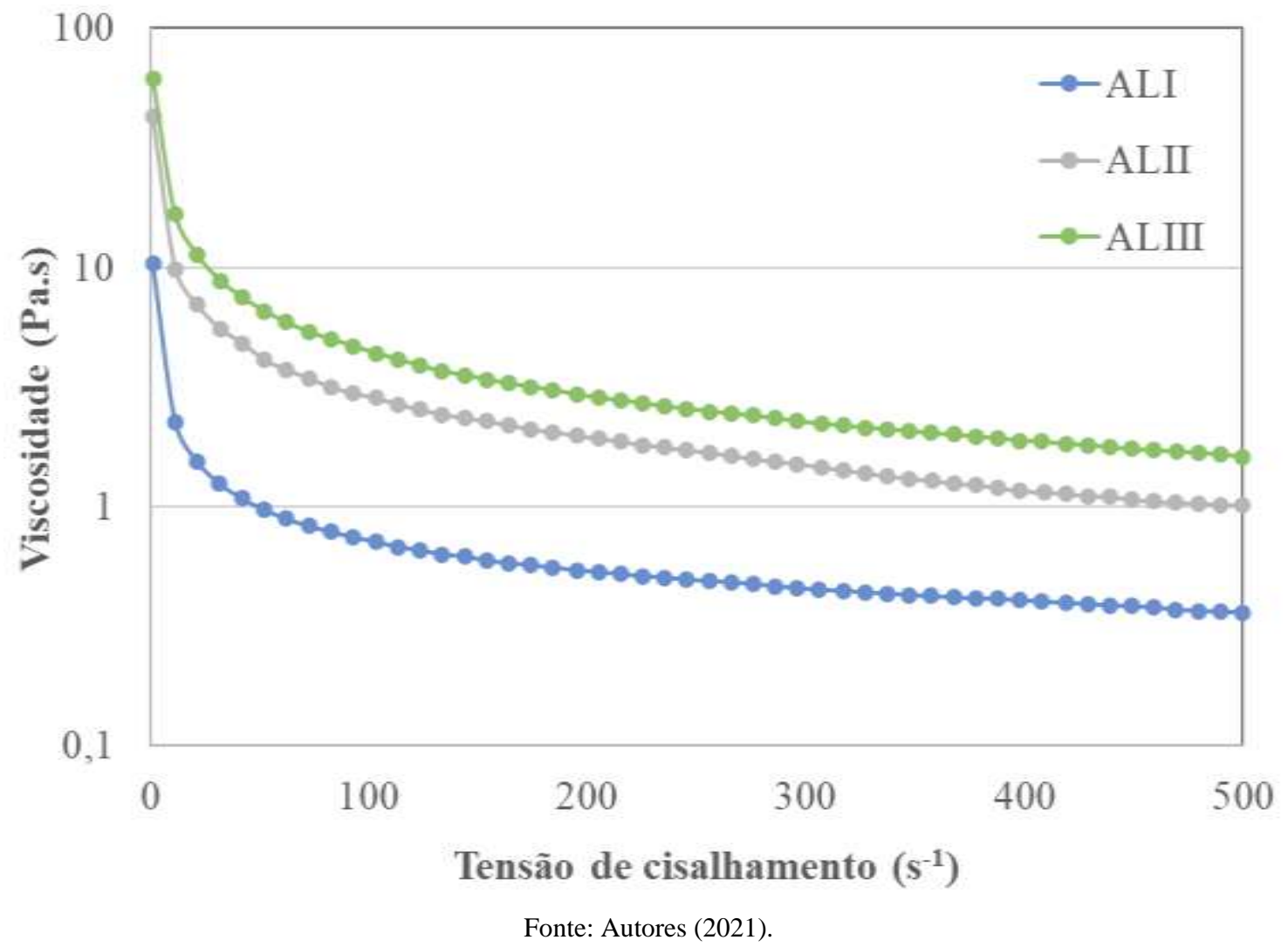


Figura 11 - Curvas de tensão de cisalhamento (Pa.) das amostras de requeijões cremosos AAI (ácido acético amostra 1), AAII (ácido acético amostra 2), AAIII (ácido acético amostra 3).

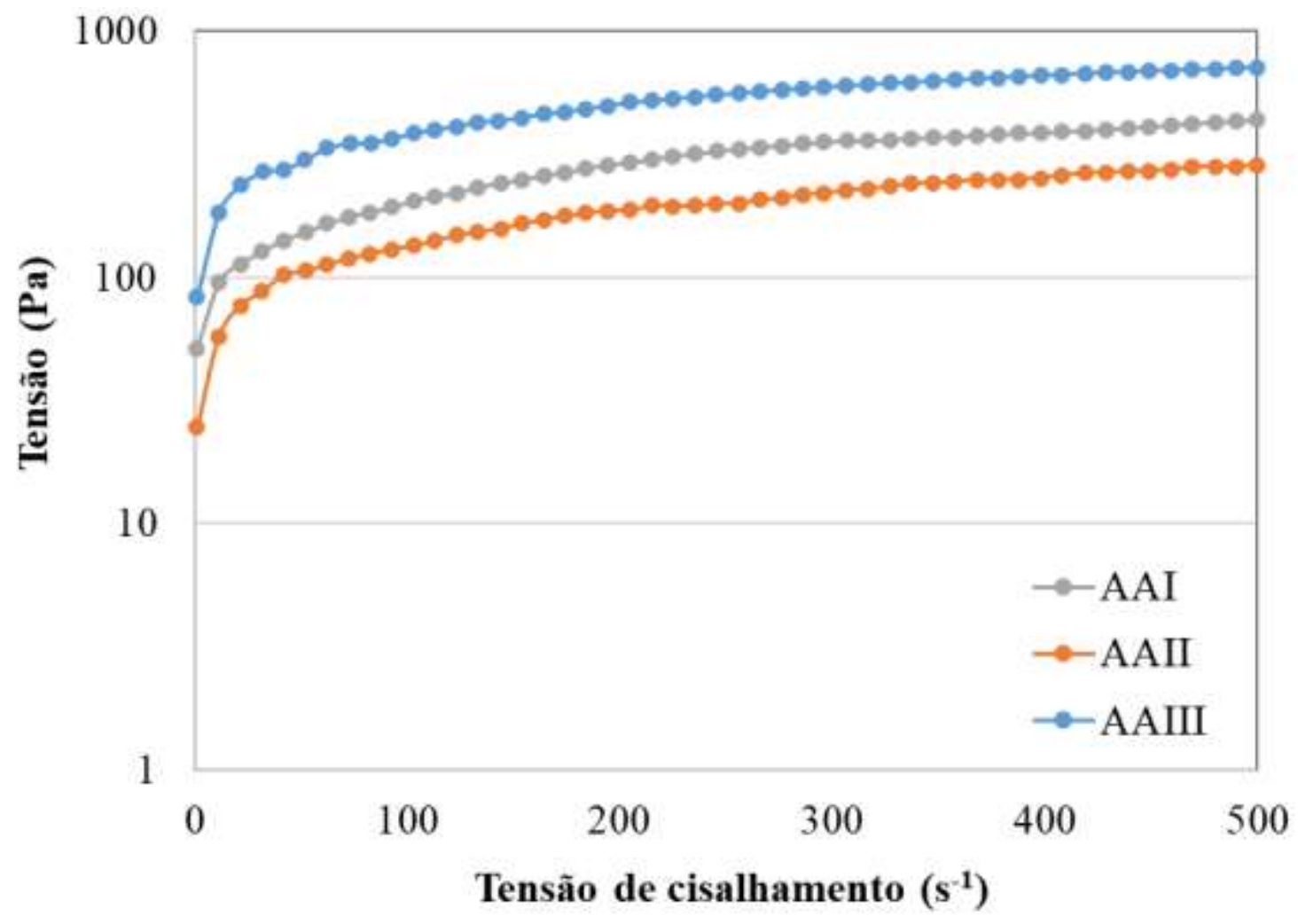

Fonte: Autores (2021).

Figura 12 - Curvas de tensão de cisalhamento (Pa.) das amostras de requeijões cremosos ACI (ácido cítrico amostra 1), ACII (ácido cítrico amostra 2), ACIII (ácido cítrico amostra 3).

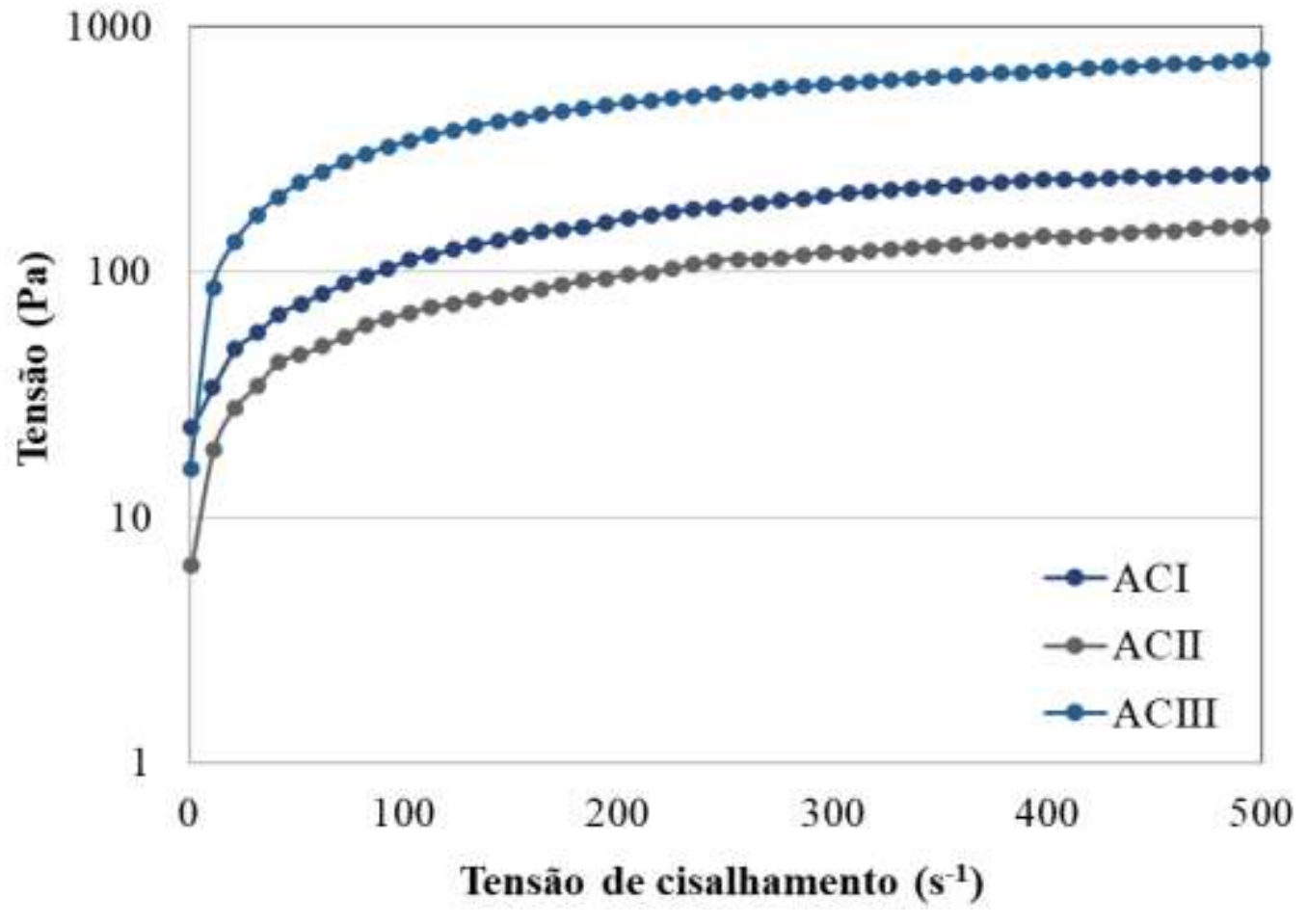

Fonte: Autores (2021). 
Figura 13 - Curvas de tensão de cisalhamento (Pa.) das amostras de requeijões cremosos ALI (ácido lático amostra 1), ALII (ácido lático amostra 2), ALIII (ácido lático amostra 3).

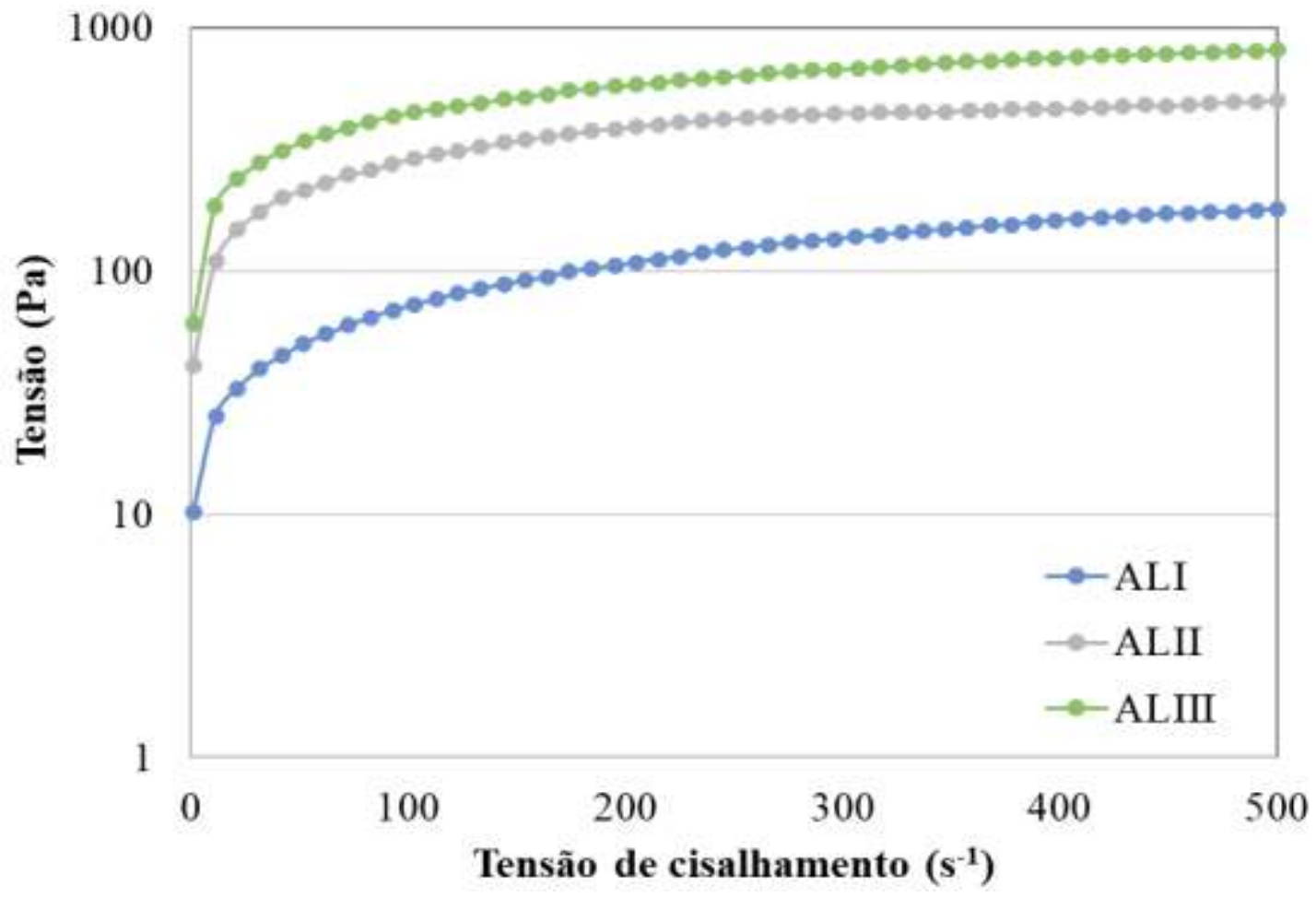

Fonte: Autores (2021).

Tabela 5 - Valores médios de k (Pa.s) consistency index, n (índice de comportamento), desvio padrão e coeficiente de variação das amostras dos requeijões cremosos, AA (ácido acético), AC (ácido cítrico) e AL (ácido lático).

\begin{tabular}{ccccccc}
\hline \multicolumn{7}{c}{ Lei da Potência } \\
\hline Amostras & $\mathbf{k}$ & $\mathbf{D p}$ & $\mathbf{c v}$ & $\mathbf{n}$ & $\mathbf{d p}$ & $\mathbf{C v}$ \\
\hline AAI & 26,17 & 0,34 & 1,31 & 0,43 & 0,03 & 6,60 \\
AAII & 17,69 & 0,60 & 3,42 & 0,44 & 0,02 & 4,27 \\
AAIII & 54,18 & 18,88 & 34,85 & 0,40 & 0,03 & 7,39 \\
ACI & 13,12 & 4,72 & 35,95 & 0,48 & 0,07 & 14,62 \\
ACII & 5,54 & 0,38 & 6,78 & 0,54 & 0,01 & 1,63 \\
ACIII & 42,86 & 11,00 & 25,67 & 0,46 & 0,05 & 10,42 \\
ALI & 4,02 & 1,85 & 45,87 & 0,61 & 0,06 & 9,97 \\
ALII & 51,91 & 6,33 & 12,19 & 0,37 & 0,01 & 3,86 \\
ALIII & 74,92 & 0,97 & 1,29 & 0,39 & 0,00 & 0,79 \\
\hline
\end{tabular}

Valores médios de k (Pa.s), (índice de comportamento), desvio padrão e coeficiente de variação das amostras dos requeijões cremosos. Fonte: Autores (2021).

$\mathrm{Na}$ avalição estatística da Tabela 5, representa valores médios de k (Pa.s), (índice de comportamento das amostras de requeijões cremosos nas Figuras 14 e 15. 
Figura 14 - Valores médios de k (Pa.s) das amostras de requeijões cremosos: AAI (ácido acético amostra 1), AAII (ácido acético amostra 2), AAIII (ácido acético amostra 3); ACI (ácido cítrico amostra 1), ACII (ácido cítrico amostra 2), ACIII (ácido cítrico amostra 3). ALI (ácido lático amostra 1), ALII (ácido lático amostra 2), ALIII (ácido lático amostra 3).

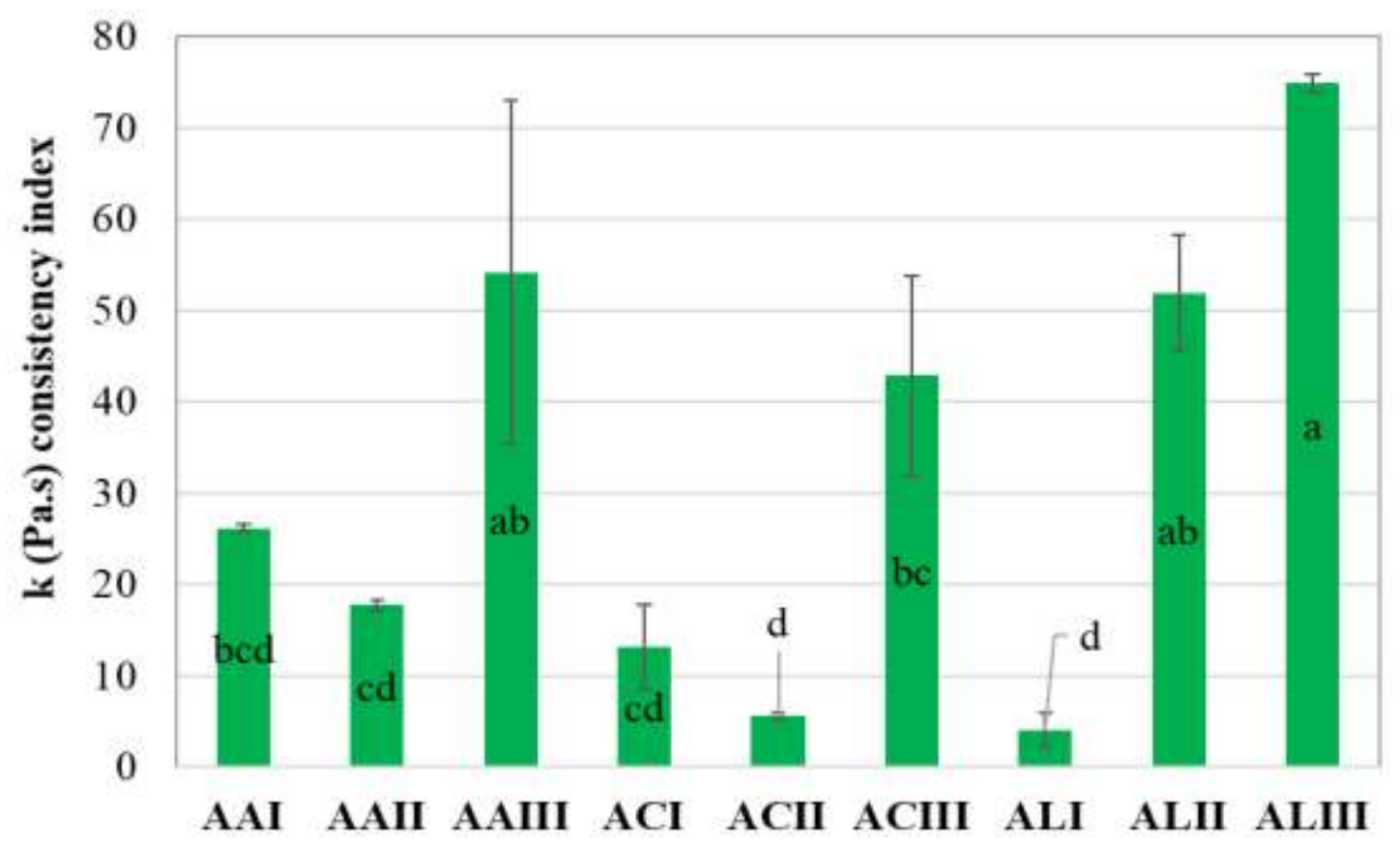

Fonte: Autores (2021).

Figura 15 - Valores médios n (índice de comportamento) das amostras de requeijões cremosos: AAI (ácido acético amostra 1), AAII (ácido acético amostra 2), AAIII (ácido acético amostra 3); ACI (ácido cítrico amostra 1), ACII (ácido cítrico amostra 2), ACIII (ácido cítrico amostra 3). ALI (ácido lático amostra 1), ALII (ácido lático amostra 2), ALIII (ácido lático amostra 3).

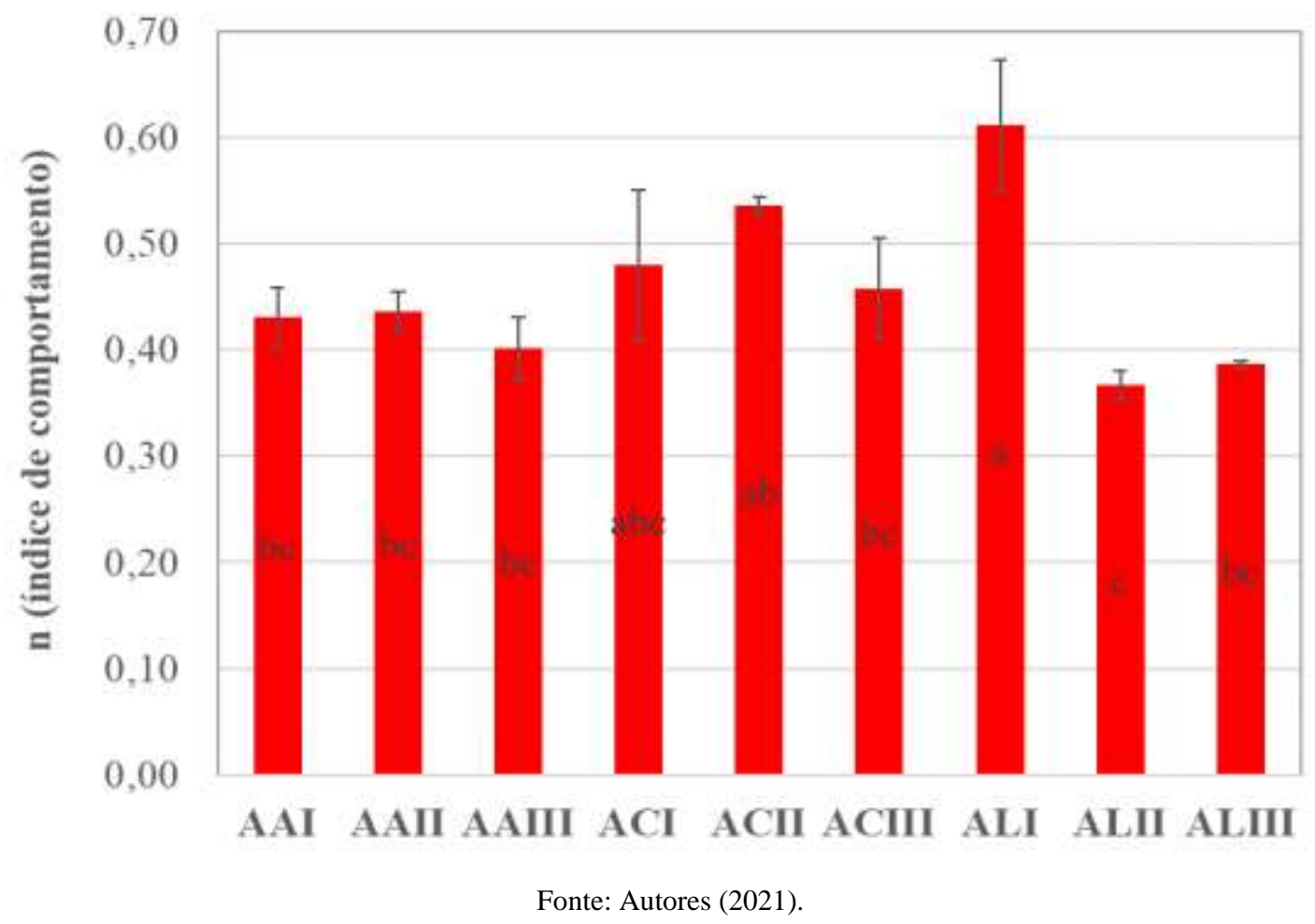




\section{Conclusão}

O desnate do leite reduz gorduras, sólidos totais, células somáticas e ureia, e aumenta proteína, lactose, sólidos desengordurados e caseína. O que é ocasionado pela extração de 9,88\% de creme do leite integral.

Os ácidos acético, cítrico e lático não afetaram o pH da massa após coagulação, porém, o maior rendimento de massa utilizada no processamento dos requeijões foi observado com o coagulante ácido cítrico.

O uso dos ácidos acético, cítrico e lático afeta a composição dos requeijões cremosos, sendo que o teor de gordura aumentou e o teor proteico reduziu, com o uso de ácido cítrico, o que promoveu variações nos parâmetros instrumentais de cor dos requeijões cremosos.

Com esta pesquisa, sugere-se à indústria de alimentos a possibilidade de oferecer requeijões cremosos com ácido lático e acético para melhor aceitabilidade do consumidor na compra do produto que notoriamente avaliando da na escala de cinco pontos na intenção de compra.

O resultado das propriedades sensoriais obtidas pela metodologia CATA, e análise de correspondência permitiu verificar a melhor aceitabilidade entre os requeijões cremosos, principalmente no atributo textura, que demostrou o requeijão cremoso elaborado com ácido acético e lático de melhor aceitação e menor ácido cítrico.

Como sugestão para trabalhos futuros, acredita-se que seria de grande valia o estudo com outros tipos de ácidos, com o objetivo de obter de forma mais abrangente os efeitos ocasionados na produção dos requeijões cremosos.

\section{Referências}

Alves, M. P., de Oliveira Moreira, R., Júnior, P. H. R., de Freitas Martins, M. C., Perrone, Í. T., \& de Carvalho, A. F. (2014). Soro de leite: tecnologias para o processamento de coprodutos. Revista do Instituto de Laticínios Cândido Tostes, 69(3), 212-226.

Antúnez, L., Vidal, L., de Saldamando, L., Giménez, A., \& Ares, G. (2016). Comparison of consumer-based methodologies for sensory characterization: Case study with four sample sets of powdered drinks. Food quality and preference, 56, 149-163.

AOAC, Association Of Official Analytical Chemists (2005). Official Methods of Analysis (No. 945.46 A18 2005) of AOAC International.

Balthazar, C. F., Santillo, A., Figliola, L., Silva, H. L., Esmerino, E. A., Freitas, M. Q., \& Albenzio, M. (2018). Sensory evaluation of a novel prebiotic sheep milk strawberry beverage. $L W T, 98,94-98$.

Bayarri, S., Carbonell, I., \& Costell, E. (2012). Viscoelasticity and texture of spreadable cheeses with different fat contents at refrigeration and room temperatures. Journal of dairy science, 95(12), 6926-6936.

Beux, S., Pereira, E. A., Cassandro, M., Nogueira, A., \& Waszczynskyj, N. (2017). Propriedades de coagulação do leite e métodos de detecção. Ciência Rural, 47(10).

Brasil, Ministério da Agricultura, Pecuária e Abastecimento. Instrução Normativa No 76, De 26 De Novembro De 2018 . Regulamentos Técnicos que fixam a identidade e as características de qualidade que devem apresentar o leite cru refrigerado, o leite pasteurizado e o leite pasteurizado tipo A. Diário Oficial da União, Brasília, 30 de novembro de 2018.

Brasil, Ministério da Agricultura, Pecuária e Abastecimento. Secretaria de Defesa Agropecuária. Portaria nº 146 , de 07 de março de 1996. Aprova os Regulamentos Técnicos de Identidade e Qualidade dos Produtos Lácteos.

Brasil, Ministério da Agricultura, Pecuária e Abastecimento. Secretaria de Defesa Agropecuária. Portaria nº 356 , de 04 de setembro de 1997. Regulamento Técnico para Fixação de Identidade e Qualidade de Queijo Processado ou Fundido, Processado Pasteurizado e Processado ou Fundido U.H.T (UAT).

Brasil, Ministério da Agricultura, Pecuária e Abastecimento. Secretaria de Defesa Agropecuária. Portaria nº 359 , de 04 de setembro de 1997 . Aprovar o Regulamento Técnico para Fixação de Identidade e Qualidade do Requeijão ou Requesón.

Brasil, Ministério da Agricultura, Pecuária e Abastecimento. Secretaria de Defesa Agropecuária. Instrução Normativa Nº 68 , DE 12 Dezembro DE 2006. Métodos Analíticos Oficiais Físico-Químicos Para Controle De Leite E Produtos Lácteos.

Brasil, Ministério da Agricultura, Pecuária e Abastecimento. Secretaria de Defesa Agropecuária. Instrução Normativa ${ }^{\circ} 62$, de 29 de dezembro de 2011.

Brasil, Ministério da Saúde/ANVISA. Agência Nacional de Vigilância Sanitária. Portaria nº 540 - SVS/MS, de 27 de outubro de 1997. Regulamento Técnico: Aditivos Alimentares - definições, classificação e emprego. Diário Oficial da União; Poder Executivo. SVS/MS - Ministério da Saúde. Secretaria de Vigilância Sanitária.

Brasil, Ministério da Saúde/ANVISA. Agência Nacional de Vigilância Sanitária. RDC no 275 de 21 de outubro de 2002 . Aprova o regulamento técnico de procedimentos operacionais padronizados aplicados aos estabelecimentos produtores / industrializadores de alimentos. Diário Oficial da República Federativa do Brasil. Brasília, 26 de outubro de 2002. 
Brighenti, M., Govindasamy-Lucey, S., Jaeggi, J. J., Johnson, M. E., \& Lucey, J. A. (2018). Effects of processing conditions on the texture and rheological properties of model acid gels and cream cheese. Journal of dairy science, 101(8), 6762-6775.

Cheng, N., Barbano, D. M., \& Drake, M. (2019). Effects of milk fat, casein, and serum protein concentrations on sensory properties of milk-based beverages. Journal of dairy science, 102(10), 8670-8690.

Cruz, A., Oliveira, C., Corassin, C. H., \& Sá, P. (2017). Processamento de produtos lácteos: queijos, leites fermentados, bebidas lácteas, sorvete, manteiga, creme de leite, doce de leite, soro em pó e lácteos funcionais (Vol. 3). Elsevier Brasil.

Dagostin, J. L. A. (2011). Avaliação de atributos microbiológicos e físico-químicos de queijo minas frescal elaborado a partir de leite carbonatado.

Dal Castel, A. P., Endres, C. M., de Freitas, A. B., \& Rodrigues, V. M. (2017). Desenvolvimento De Requeijão Cremoso Sem Lactose. Revista do Instituto de Laticínios Cândido Tostes, 72(2), 58-66.

Damodaran, S., \& Parkin, K. L. (2018). Química de alimentos de Fennema. Artmed Editora.

dos Santos Navarro da Silva, R., Rodrigues Minim, V. P., Ribeiro Teixeira Vidigal, M. C., Almeida Teixeira, J., da Silva Moraes, L. E., Lima, L. P., \& Minim, L. A. (2012). Teor de gordura e de água: fatores determinantes na textura e na aceitabilidade de requeijão light. Revista do Instituto Adolfo Lutz (Impresso), 71(1), 118-126.

Ferrão, L. L., Ferreira, M. V. S., Cavalcanti, R. N., Carvalho, A. F. A., Pimentel, T. C., Silva, H. L., \& Cruz, A. G. (2018). The xylooligosaccharide addition and sodium reduction in requeijão cremoso processed cheese. Food research international, 107, 137-147.

Ferreira, D. F. (2011). Sisvar: a computer statistical analysis system. Ciência e agrotecnologia, 35(6), 1039-1042.

Fragoso, A. M., Nigelski, S. B., \& Bovaroti, T. (2012). Avaliação da estabilidade de sobremesa láctea cremosa potencialmente probiótica (Bachelor's thesis, Universidade Tecnológica Federal do Paraná).

Garruti, D. D. S., Brito, E. S. D., Brandão, T. M., Uchôa Jr, P., \& da Silva, M. A. A. (2003). Desenvolvimento do perfil sensorial e aceitação de requeijão cremoso. Food Science and Technology, 23(3), 434-440.

Hoffmann, C. D. M. (2003). Estudo da utilização de concentrado proteico de soro de queijo ultrafiltrado (CPSU), em requeijão cremoso.

Kontou, V., Dimitreli, G., \& Raphaelides, S. N. (2019). Elongational flow studies of processed cheese spreads made from traditional greek cheese varieties. $L W T, 107,318-324$.

Lima, K. R. L. (2019). Perfil Físico-Químico De Requeijão Cremoso Obtido A Partir De Diferentes Coagulantes.

Maderi, T. R. (2014). Diagnóstico da gestão integrada em indústrias de laticínios do Território de Identidade do Médio Sudoeste (Doctoral dissertation, Dissertação de mestrado). Programa de Pós-graduação em Engenharia e Ciência de Alimentos, Universidade Estadual do Sudoeste da Bahia, Itapetinga).

Mathias, T. R. D. S., Andrade, K. C. S., Rosa, C. L. D. S., \& Silva, B. A. (2013). Avaliação do comportamento reológico de diferentes iogurtes comerciais. Brazilian Journal of Food Technology, 16(1), 12-20.

Moraes, B. M. M., \& Bender Filho, R. (2017). Mercado Brasileiro de Lácteos: análise do impacto de políticas de estímulo à produção. Revista de Economia e Sociologia Rural, 55(4), 783-800.

Nae, H. (2013). Rheological properties of topical formulations. Apply topically: A practical guide to formulating topical application. Vol 0. Carol Stream, IL: Allured Books, 287-348.

Oliveira, D. S., \& Timm, C. D. (2006). Composição do leite com instabilidade da caseína. Food Science and Technology, 26(2), 259-263.

Oliveira, E. W., Esmerino, E. A., Carr, B. T., Pinto, L. P. F., Silva, H. L. A., Pimentel, T. C., ... \& Freitas, M. Q. (2017). Reformulating Minas Frescal cheese using consumers' perceptions: Insights from intensity scales and check-all-that-apply questionnaires. Journal of dairy science, 100(8), 6111-6124.

Paucar-Menacho, L. M., Silva, L. H. D., Barretto, P. A. D. A., Mazal, G., Fakhouri, F. M., Steel, C. J., \& Collares-Queiroz, F. P. (2008). Desenvolvimento de massa alimentícia fresca funcional com a adição de isolado protéico de soja e polidextrose utilizando páprica como corante. Food Science and Technology, 28(4), 767-778.

Pereira, A. S. et al. (2018). Metodologia da pesquisa científica. UFSM. https://repositorio.ufsm.br/bitstream/handle/1/15824/Lic_Computacao_MetodologiaPesquisa-Cientifica.pdf?sequence= 1 .

Perveen, K., Alabdulkarim, B., \& Arzoo, S. (2011). Effect of temperature on shelf life, chemical and microbial properties of cream cheese. African Journal of Biotechnology, 10(74), 16924-16928.

Pflanzer, S. B., Hatanaka, C. L., Mamede, P. L., Cadena, R., Faria, J. A. F., \& da Silva, M. A. A. P. (2010). Perfil sensorial e aceitação de bebida láctea achocolatada. Ciência e Tecnologia de Alimentos, 30(2), 391-398.

Pinto, A. M. (2015) Estudo da homogeneização e teor de gordura na produção de cream cheese. Dissertação Mestrado Profissional em Ciência e Tecnologia de Alimentos Instituto Federal do Triângulo Mineiro Campus Uberaba, Minas Gerais.

Presente, J. G. (2015). Produção e conservação de queijos frescos adicionados de óleos essenciais. Universidade Federal do Rio Grande escola de química e alimentos engenharia agroindustrial e indústrias alimentícias, Santo Antônio da Patrulha.

Saath, K. C. D. O., \& Fachinello, A. L. (2018). Crescimento da demanda mundial de alimentos e restrições do fator terra no Brasil. Revista de Economia e Sociologia Rural, 56(2), 195-212. 
Research, Society and Development, v. 10, n. 2, e33710212455, 2021

(CC BY 4.0) | ISSN 2525-3409 | DOI: http://dx.doi.org/10.33448/rsd-v10i2.12455

Schramm, G. (1994). A practical approach to rheology and rheometry (pp. 20-25). Karlsruhe: Haake.

Silva, A. T., Spadoti, L. M., Zacarchenco, P. B., \& Van Dender, A. G. F. (2015). Desenvolvimento de tecnologia de fabricação de requeijão cremoso com teor reduzido de gordura. Revista do Instituto de Laticínios Cândido Tostes, 70(2), 64-77.

Sobral, D. (2007). Otimização do processo de fabricação de análogos de requeijão culinário. Campinas, São Paulo, Universidade de Campinas.

Talbot-Walsh, G., Kannar, D., \& Selomulya, C. (2018). A review on technological parameters and recent advances in the fortification of processed cheese. Trends in Food Science \& Technology, 81, 193-202.

TORRES, F. R. (2015). Estudo Das Características Sensoriais, Físicas E Químicas Em Requeijão Cremoso Tradicional E Adicionado De Amido E Gordura Vegetal, Obtidos No Comércio Varejista. Universidade Federal Fluminense Faculdade de Veterinária Programa de Pós-Graduação em Higiene Veterinária e Processamento Tecnológico de Produtos de Origem Animal.

Torres, F. R., Esmerino, E. A., Carr, B. T., Ferrão, L. L., Granato, D., Pimentel, T. C., \& Cruz, A. G. (2017). Rapid consumer-based sensory characterization of requeijão cremoso, a spreadable processed cheese: Performance of new statistical approaches to evaluate check-all-that-apply data. Journal of Dairy Science, $100(8), 6100-6110$.

Tucker, G. (2017). Applications of rheological data into the food industry. In Advances in Food Rheology and Its Applications (pp. 159-175). Woodhead Publishing.

Vilela, D., Resende, J. C. D., Leite, J. B., \& Alves, E. (2017). A evolução do leite no Brasil em cinco décadas. Revista de Política Agrícola, $26(1)$, 5-24.

Williams, S. (1984). Official methods of analysis (No. 630.24 A8 1984). Association of Official Analytical Chemists.

Zacarchenco, P. B., Costa, A. M., Trento, F., Czaikoski, A., Spadoti, L., \& Van Dender, A. G. F. (2017). Caracterização de massa básica de requeijão obtida por acidificação direta a quente a partir de leite lactosehidrolisado. In Embrapa Cerrados-Artigo em anais de congresso (ALICE). In: Congresso Nacional De Laticínios, 31. 2017, Juiz de Fora. [Anais...]. Juiz de Fora: Instituto de Laticínios Cândido Tostes, 2017. 